NBER TECHNICAL PAPER SERIES

\begin{abstract}
THE ROLE OF ECONOMIC POLICY AFTER THE
\end{abstract}
NEW CLASSICAL MACROECONOMICS

\author{
Willem H. Buiter
}

Technical Paper No. $\underline{6}$

NATIONAL BUREAU OF ECONOMIC RESEARCH

1050 Massachusetts Avenue

Cambridge MA 02138

November 1980

This paper was presented at the AEA meetings in Atlanta, in December 1979, and at the AUTE meetings in Durham, March 1980. (Revised in March 1980). The research reported here is part of the NBER's research program in International Studies. Any opinions expressed are those of the author and not those of the National Bureau of Economic Research. 
The Role of Economic Policy After the New Classical Macroeconomics

\begin{abstract}
The paper considers the implications of the rational expectations - New Classical Macroeconomics revolution for the "rules versus discretion" debate. The following issues are covered 1) The ineffectiveness of anticipated stabilization policy, 2) Non-causal models and rational expectations, 3) optimal control in non-causal models -the inconsistency of optimal plans. I established the robustness of the proposition that contingent (closedloop or feedback) rules dominate fixed (open-loop) rules. The optimal contingent rule in non-causal models - the innovation or disturbance-contingent feedback rule - is quite different from the state-contingent feedback rule derived by dynamic stochastic programming .
\end{abstract}

Willem H. Buiter Department of Economics University of Bristol 40 Berkeley Square Bristol BS8 1HY ENGLAND 0272-24161, ext. 67 


\section{The Role of Economic Policy After the New Classical Macroeconomfcs}

Willem H. Buiter,

\section{Introduction}

The stagflation of the past 15 years appears to have underinined conventional neo-Keynesian economics in the same way the Great Depression undernined neoclassical economics in the 1930s. The economic collapse of the thirties destroyed the faith of many in the self-regulating properties of the "unaided" decentralized market economy and motivated a major increase in the role of government in economic affairs. The worsening economic muddle of the late sixties and the seventies has seriously undermined neo-Keynesian optimism about the ability of governments to select attractive combinations of output, employment, inflation and external balance through the judicious use of fiscal, monetary, financial and exchange rate policy. "Fine tuning;" the sensitive response of monetary and fiscal instruments to even minor disturbances in economic activity, has acquired an especially bad name.

The skepticism about the ability of governments to use stabilization policy wisely has been matched by an increasingly vocal criticism of structural policy. By structural policies I mean policies that alter the level and composition of full employment output and employment, both in the short run--for a given capital stock and state of technology--and in the long run, when the size and composition of the capital stock and the state of technology are endogenous. Stabilization policies are policles that influence (and, one hopes, minimize) deviations of output 
and employment from their full employment ("natural" or "equilibrium") levels. The view advanced by Bacon and Eltis [1978] that the nonmarket sector has encroached unduly on the market sector represents a criticism of past and present structural policies. Policies aimed at altering the relative size of the public and private sectors or at changing a nation's consumption-investment mix are structural policies, as are policies designed to favor the primary, secondary or tertiary sectors. The Laffer curve is the conceptual foundation of structural tax policy proposals. Policies that influence the "natural" rate of unemployment (e.g. minimum wage laws) are structural policies.

If stabilization policies were defined to include only those policies that affect the fluctuations of output and employment around their "natural" levels without having any short-run or long-run effects on these "natural" .. levels themselves, the stabilization policy set would be the empty set. In virtually every macroeconomic or macroeconometric model that is not strictly for classroom use only, the distinction between the two kinds of policies is quite arbitrary. Certainly, every real-world economic policy action has both stabilization and structural consequences. This is, of course, quite consistent with ill-informed policymakers considering only either the stabilization, or the structural consequences of their actions, and fgnoring half the implications of their policies. Some of the most serious dilemmas in economic policymaking occur when a policy that is desirable for its short-run stabilization effects has undesirable long-run structural implications or vice versa. Cutting government spending to reduce demand pressures in an overheated economy may lead to painful changes in the 
composition of output away from the proviston of public consumption goods or from investment in social overhead capital. A desire to reduce the (relative) size of the public sector may result in a slump when the cut in public spending is not immediately matched by an equivalent expansion of private domestic or external demand.

The practical impossibility of identifying a pure stabilization polfcy that does not have any structural implications is of some importance when the policy conclusions of the New Classical Macroeconomics School are discussed below. A plausible interpretation of some of the writings of this school is that (at least) two pure stabilization policles exist. The first is monetary policy--the control of the nominal stock of high-powered money. The second is deficit financing--the substitution of borrowing (and sometimes also money financing) for lump-sum tax financing of a given level and composition of real exhaustive public spending. This view is incorrect: both these policles have structural consequences.

I consider the retreat from neo-Keynesian policy optimism both understandable and appropriate. In the light of the accumulated empirical evidence of the last 15 years some critical revaluation of the conventional wisdom of the fifties and the early sixties is clearly required. What is harder to understand is how, for so many, this retreat from the neo-Keynesian mainstream and from policy optimism has taken the form of a return to the neoclassical dogmas and modes of analysis that recelved. such a battering in the thirties. The most convincing explanations for this curious phenomenon are the gradual passing of the generations whose consciousness was shaped during the Great Depression and the fallure to 
teach economic history at all serfously in many contemporary graduate economics programs.

The revival of pre-thirties macroeconomics which is now widely referred to as the New Classical Macroeconomics is associated historically with Milton Friedman [1968] but has achieved its recent prominence as a result of the work of Edmund Phelps [1970], Robert Lucas [1972a, b, 1975, 1976], Thomas Sargent and Nefl Wallace [1975, 1976], Robert Barro [1974, 1976, 1979], Edward Prescott [1975, 1977], Finn Kydland and Edward Prescott [1977], Bennett McCallum [1977, 1978], Robert Hall [1970, 1979], and a host of others. The major improvement of the modern variant over the original, as represented, e.g., in the works of Hayek [1932, 1939], Knight [1941], Douglas [1932, 1935], Hawtrey [1926], Haberler [1932] and Fisher [1933], reflects the considerable progress made since the thirties in the tech..

nical aspects of economic analysis. We know now how to formally analyze simple, preferably linear, stochastic processes. A not entirely facetious characterization of the New Classical Macroeconomics is to regard it as a formalization of certain aspects of the old classical macroeconomics with white noise added. The new version compares unfavorably with the old one, however, in its unsophisticated treatment of the money supply process and of financial markets in general. The old classical macroeconomics was also more flexible in recognizing the possibility of departures from ideal competitive behavior in goods, factor and financlal markets during cyclical upswings or downturns, although no formal characterization of such departures was ever provided.1/ 
This paper analyses the implications of the New Classical Macro-

economics for the conduct of economic policy. The focus of the analysis is on what used to be called "rules versus discretion" but should be called fixed rules (rules without feedback or open-loop rules) versus flexible rules, i.e. rules with feedback, contingent rules or closed-loop rules. With openloop policies the values of the actual time paths of the policy variables are specified at the beginning of a planning period and are functions only of the information available at the beginning of the planning period. These paths . are not state-dependent: they are to be followed by the policymaker without regard to future events or to any new information that may accrue as time passes. Milton Friedman's advocacy of a fixed growth rate for some monetary aggregate is an example of a very simple kind of open-loop rule. Closed-loop, contingent or feedback policies specify the values of the policy variables in period $t$ as known functions of the information that will be available when a value will actually have to be assigned to the policy instruments, but may not yet be available in earlier periods. Thus future policy instruments are known functions of observations yet to be made. There is no sexious disagreement that policy should be determined by rules. Views differ as regards the desirability of rules without feedback versus rules with feedback or contingent rules.

The application of stochastic dynamic programing to dynamic models in statespace form leads to optimal contingent (feedback) rules that in models with uncertainty dominate any open-loop rule. In view of this, how can anyone argue that open-loop rules should be adopted? The common-sense reason for the superiority of contingent rules over fixed rules -- that one can never do worse by permitting a flexible (but known) response to new information -- seems robust.

There are three distinct foundations for the view that open-loop policies are superior to closed-loop rules. The first argument does not contest the proposition that monetary, fiscal and financial policies, anticipated and unanticipated, have important real effects, short run and/or long run. However, these effects come with lags that are often long and are always variable and uncertain. In such an environment, even a well-informed and well-intentioned policy maker is likely. to have 
a difficult time determining the optimal feedback rule. Real-world

governments are frequently neither well-informed nor well-intentioned.

It is therefore preferable to constrain the policy authorities' options by comitting them to simple fixed rules such as a constant growth rate for the money supply or a balanced budget, if necessary by constitutional amendment. This view has been advanced most forcefully by Milton Friedman. It reflects a very practical concern about the wisdom of leaving powerful instruments with uncertain effects in the hands of persons or agencles with limited abllity and sometimes dubious motives. Although I consider it to be the most powerful of the three argunents in favor of fixed rules, I shall not discuss it any further, as it antedates the New Classical Macroeconomics.

The second argument is that economic policy-mainly stabilization policy and often only monetary policy--is irrelevant for the behavior of the real economy to the extent that 1 is is anticipated. Known, deterministic policy rules, open-loop or feedback, have no effect on the joint probability density functions of real economic variables. Applications of this view to monetary policy can be found in Sargent and Wallace [1975] and Barro [1976]. Barro [1974] applied 1t to deficit financing: the substitution of bond financing (and money financing?) for (1ump-sum) tax financing of a real spending program has no real consequences. McCallum [1977] argued that $1 \mathrm{t}$ held for all forms of stabilization policy. This second argument does not question the wisdom of attempts at stabilization policy, it questions the very possibility of stabilization policy. Since any known policy rule will have no real effects, the only contribution of the government to economic stabilization consists in not introducing 
additional uncertainty into the economy by having an unknown, stochastic policy rule. In principle any known feedback rule is as neutral is any known open-loop rule. In practice, however, instrument uncertainty is likely to be minimized by the selection of the simplest possible fixed rule. The foundations for the second argument, that only unanticipated (stabilization) policy has real effects are analyzed in Section II. They are found wanting.

The third argument takes aim at the application of traditional optimal control techniques based on dynamic programming to the derivation of optimal economic policies in models with optimizing agents endowed with rational expectations of the future. It is a criticism of the theory of optimal economic policy rather than of the actual conduct of economic policy. Traditional optimal control approaches for models in state-space form lead to optimal policy rules that in models with uncertainty must be expressed in feedback or closed-loop form. In models without uncertainty and one optimizing agent, the optimal policy can be expressed equivalently in closed-loop or open-loop form. Kydland and Prescott [1977] have shown that policies derived by dynamic programming, which they call "consistent" policies, are sub-optimal in models with optimizing agents endowed with rational expectations of the future whose anticipations of the future affect the current state, because such consistent policies fail to allow for the effect of anticipated future instrument values on current (and past) states. The optimal policy in such models, they argue, is an open-loop rule. To lay the grouncwork for an analysis of this proposition, Section III briefly considers the impact of the "rational expectations revolution." Section IV deals with causal and noncausal solutions of dynamic systems and optimal 
control in causal systems with many optimizing players. Section V considers policy optimization in noncausal models. The conclusion reached by Kydland and Prescott that the consistent policy is suboptimal is confirmed. However, it is also shown that, in models with uncertainty, there always exists a feedback policy (called an "innovation-coningent" feedback policy) that dominates the optimal open-loop policy. Only in models without uncertalnty is the optimal open-loop policy truly optimal.

I conclude that, with the exception of the demonstration of the inapplicability of traditional dynamic programming methods in noncausal models, the open-loop versus closed-loop debate stands where Milton Friedman left it. Further progress has to wait for the development of substantive economic models out of an emerging New Keynesian Macroeconomics.

II. The Three Fundamental Assumptions of the New Classical Macroeconomics

Underlying the New Classical Macroeconomics propositions about the ineffectiveness of anticipated stabilization policy are three fundamental assumptions.

1. Identical public and private opportunity sets or the public sectorprivate sector Modigliani-Miller Theorem

This is the assumption that there is nothing the government can do through stabilization policy that decentralized, competitive private agents cannot undo, as long as the government action is anticipated. More than this, competitive private agents can and will undo any anticipated government action without by so doing altering any real equilibrium condition in the system. Four examples of what this implies in the context of stabilization policy are the following: 
a. Private agents must be able to tax and transfer on the same terms as the government. This is essential if there are to be no real effects from the substitution of bond financing for tax financing. The institutional, legal fact that private agents cannot legally impose a negative transfer on other private agents, 1.e., that private agents cannot tax is one reason for Barro's debt neutrality theorem to break down even if private agents have two-sided intergenerational gift motives (Barro [1974], Carmfchael [1979], Buiter [1979, 1980a], Tobin and Bufter [1980], Bufter and Tobin [1980]).

b. Private interest-bearing debt must be a perfect substitute, in private and public portfollos, for public interest-bearing debt. If this is not the case, real changes will occur when the government net worth position changes from being a net creditor to being a net debtor. More generally, changes in the volume of public sector lending or borrowing will alter the opportunity set facing private portfolio holders if public and private bonds are not perfect substitutes. The perfect substitutes assumption is clearly a very painful one, in view of the observed inability of even large private corporations to borrow on the same terms as the Federal government. Differential default risk, partly a function of the private sector's inability to tax (discussed under "a") and partly a function of the public sector's unique ability to declare (part of) its (noninterest-bearing) liabilitles legal tender (discussed under "c" below), is a sufficient reason for the perfect substitutes assumption to be unacceptable. 
c. Private agents can tssue financial claims that are perfect substitutes for legal tender (noninterest-bearing government-controlled fiat money). The special position occupied by noninterest-bearing government fiat money in the New Classical Macroeconomics literature is not derived from acceptable, explicit economic first principles. This unsatisfactory state of affairs of course characterizes virtually all of past and present macroeconomics. Fiat money should be wanted nelther as a consumption good nor as a capital good. It is only held because it represents future purchasing power over consumer goods or capital goods. Consider an economy with noninterest-bearing government fiat money and default-free, flxed nominal market value, interest-bearing government bonds. Private transactions costs, a la Baumol-Tobin (Baumol [1952], Tobin [1956] or Miller and orr [1966]), are required to explain the coexistence of noninterestbearing govermment money and riskless interest-bearing government bonds (Bryant and Wallace [197,9]). The substitution of money financing of public spending for bond financing will therefore have real effects, as will open market operations in money and bonds. To rule out such real effects it is necessary to assume that the money controlled by the government (whether this consists only of high-powered money or includes government-controlled bank money) is perfectly substitutable, as a store of value and a medium of exchange, with other privately issued, uncontrolled financial claims. This would salvage the Modigliant-Miller theorem for open market operations In money and bonds at the cost of loss of government control over the total effective money supply, controlled plus uncontrolled. It also raises the theoretical specter of indeterminacy of the general price level. 
d. The private sector can respond to new information by changing its controls (labor supply, consumption, portfollo allocation, sales, etc.) at least as fast as the public sector can alter any of its controls. If the public sector can change at least one of 1 ts instruments (e.g., the money supply) continuously, while the private sector is locked into predetermined nominal contracts for finite periods, deterministic money supply rules will have real effects (Fischer [1977], Phelps and Taylor [1977] and Taylor [1978]). Models incorporating overlapping multi-period nominal wage contracts exhibit very "Keynesian" behavior. In any given period, the majority of the labor force is covered by pre-existing nominal wage contracts. Each contract incorporates all relevant information on the behavior of the general price level and average wages over the life of the contract that was available at the date the contract was entered into. As new information becomes available in period $t$, it is reflected only in the contracts that are up for renegotiation that period. The majority of the labor force is still covered by unexpired pre-existing contracts. Management responds to "innovations" in demand by altering output and employment at these precontracted wages. If the money supply can respond to demand innovations before each and every labor contract is up for renewal, output stabilizing monetary feedback rules exist. The information sets of the monetary authorities and the private sector may be identical, but the difference in opportunity sets-in this case in the speed of response to demand innovations--creates scope for beneficial or detrimental monetary feedback rules.

The microfoundations of such multiperiod nominal wage contracts are st111 quite unsatisfactory (Barro [1977, 1978]). In the U.S. economy, at 
any rate, they are a fact of $11 f e$ and it seems unwise to deny their existence until they can be fitted into an a prioristic paradigm of how the economy ought to work.

2. Identical public and private information

More precisely, the public sector information set ${ }_{t}$ is a subset (but not necessarily a proper subset) of the private sector information set $\phi_{t} \cdot \Psi_{t} \subseteq \phi_{t}$. This assumption can be viewed as a special case of the assumption of identical public sector and private sector opportunity sets. It is mentioned separately because of the central role played by information and expectation formation in contemporary macroeconomics. Even if opportunity sets are otherwise identical, superior information may enable the public sector to respond to disturbances that cannot be identified with equal precistion or equal speed by private agents. Such responses can alter the real trajectory of the economy (Barro [1976]). It is unlikely that public sector information is unfformly superior or inferior to private sector information. Different agents have different comparative advantages in gathering, analyzing and evaluating different types of information: $\psi_{t} \nsubseteq \phi_{t}$ and $\psi_{t} \nsupseteq \phi_{t}$ seems a better characterization of the relationship between public and private information.

3. All financial, goods and factor markets are competitive, efficlent auction markets.

This third assumption can be viewed as an important part of the microeconomic foundations of the first assumption. Each and every market, real and financial, is in ideal, general, competitive equilibrium or Walrasian equilibrium all the time. Prices adjust instantaneously to current and anticipated future disturbances so as to balance notional demand and supply in each market. All agents are price takers. Households' notional demands and supplies 
are derived from expected utility maximization subject only to the constraint of the household endowment valued at market prices that are viewed as parametric by each individual agent. The notional demands and supplies of firms are derived from market value maximization subject only to the constraint of the production possibility set, with all planned sales and purchases valued at prices that are viewed as parametric by each individual firm. Households and firms (and government ?) act as if, at the prevalling set of market prices, they can buy or sell any amount of any good or service. An industrious and costless auctioneer instantaneously and continuously sets prices in all markets at levels that make these notional demands and supplies mutually consistent. $\underline{2}$

Compelling empirical evidence to support this extreme view of the way in which markets operate is seldom offered. This is not surprising, as it bears very little relation to the modus operand 1 of many labor, goods and financial markets in contemporary developed capitalist or mixed economies, as described in the labor economics, industrial organization and financlal 11terature. Instead of careful studies of market organization, a priori arguments are advanced that purport to Identify privately rational behavior and the useful concept of equilibrium with Walrasian, competitive, market-clearing equilibrium. This "equilibrium approach" is then contrasted favorably with selected ad hoc neo-Reynesian approaches (Barro [1979], Lucas and Sargent [1978]).

The characterization of the New Classical Macroeconomics as equilibrium economics does not suffice to generate the New Classical invariance or policy neutrality propositions. It is also insufficiently precise 
because of the universality of the concept of equilibrium. Equilibrium refers to a state in which optimizing agents have no incentive to alter their behavior because, conditional on their expectations, their current plans are mutually consistent and can be executed. An expectations equilibrium is a slightly stronger concept, because it also requires that agents formulate plans or strategies on the basis of optimal inferences and forecasts of current and future exogenous and endogenous variables. Until the constraints subject to which agents optimize, including their information sets, are specified, the assumption of equilibrium and optimizing behavior is essentially vacuous, because tt does not impose refutable restrictions on observable behavior. The most general version of the Walrasian competitive equilibrium model represents only a very small move towards potential falsiflability: the equilibrium values of all real variables should be homogeneous of degree zero in all current and anticipated future money prices and nominal endowments, and Walras' Law should be satisfied.

One can have optimizing, privately rational behavior and equilibrium without this equilibrium being competitive. Monopolistic competition, oligopoly and monopoly are famillar market forms. More generally, game theory, and especially its dynamic extension, differential games, offers a wide variety of equilibrium concepts, many of which are more appropriate as approximations to actual market configurations than the Walrasian competitive equilibrium (Intriligator [1971], Kydland [1975], Bacharach [1976]). Even if a competitive equilibrium concept is preferred for certain markets, this competitive equilibrium need not be an efficient, Walrasian, market- 
clearlng equilibrium. Stiglitz et. al. have developed theorles of nonmarket-clearing, quantity-constrained competitive equilibrium for markets with costly, imperfect and asymetric information (Stiglitz [1977, 1979], Grossman [1976], Akerlof [1970], Riley [1979], W11son [1977, 1979], Salop [1978, 1979]). For a somewhat different approach see Negishi [1960], Hahn [1979] and the recent survey by Drazen [1980]. Inefficient markets, e.g., those characterized by a partial (or no) immediate response of prices to innovations in cost or demand, create opportunities for known monetary and deficit financing rules to have real effects (e.g. Buiter [1980b]). Noncompetitive gametheoretic equilibria and competitive but inefficient non-Walrasian equilibria will be the cornerstones of a "New Keynesian Macroeconomics." The Walrasian, efficient competitive market-clearing equilibrium remains a useful'special case that may characterize a limited number of commodity markets and financial markets.

\section{Rational Expectations}

So far, this discussion of the New Classical Macroeconomics has proceeded without any mention of rational expectations. Historically, rational expectations in the sense of Muth [1961] have of course been an Integral part of the New Classical Macroeconomics package. The three fundamental assumptions of the New Classical Macroeconomics--"Modigliani Miller" of the public vis-a-vis the private sector, identical public and private information and efficlent markets--are, however, quite independent of the rational expectations assumption. What rational expectations do In any model, New Classical or Old Keynestan, is to eliminate the scope for government to use unanticipated policy in a systematic manner. My objections to the New Classical Macroeconomics do not extend to the rational 
expectations assumption, which is a useful and even an important addition to the economist's toolkit.

The expression "rational expectations" represents a minor abuse of language. Standard practice in economics commands that the label rational expectations be reserved for forecasts generated by a rational, i.e., expected utility maximizing decision process in which the uncertain costs of acquiring, processing and interpreting additional information are balanced against the uncertain anticipated benefits from further refinement of the forecast. As used by the New Classical Macroeconomists, rational expectatIons shortcuts the actual process of information gathering and forecasting and focuses on the long-run equilibrium outcome of a "Bayesian" sequential prediction process, when forecasting has become a fairly simple and mechan1cal procedure: the subjective probability distribution of future economic variables held at time $t$ coincides with the actual, objective conditional distribution based on the information assumed to be avallable at time $t$. $\underline{3}$ / In many applications only the first moments of these distributions are assumed to be relevant. In Muth's original contribution, e.g., (Muth [1961]), it was hypothesized that the mean expectation of firms with respect' to some phenomenon, e.g., the future price of a commodity, was equal to the prediction that would be made by the relevant, correct and universally agreed upon economic theory. Future variables anticipated at time $t$ are "true mathematical expectations of the future variables conditional on all variables in the model which are known to the public at time t" (Shiller [1978], p. 3). Analytical tractability often compels the use of linear models in which case rational expectations become least squares forecasts. 
The specialization of rational expectations to best linear unbiased predictors conditional on an information set that includes the true, objective structure of the model is a powerful simplification that greatly facilitates practical applications. It also begs a number of cructal questions. The question of how economic agents acquire their knowledge of the true structure of the economy which is used in making their rational forecasts is not addressed. The appeal of rational expectations lies in the fact that any forecasting scheme that is not rational in the sense of Muth will be consistently wrong: It will result in systematic, predictable forecast errors. Sensible economic agents will detect unexploited arbitrage opportunities which will force the abandonment of the forecasting scheme and the adoption of a new one. Economic theory has very little to say about the learning process by which unsatisfactory forecasting schemes are revised. Ultimate convergence of the revision process to a rational expectations mechanism is neither self-evident nor inevitable (De Canlo [1979]). Unless the forecasting mechanism has converged to the rational expectations scheme and economic agents know the true structure of the model, the cruclal error-orthogonality property does not hold.4/ Analytical tractability is a necessary but not a sufficlent condition for a model to be economically interesting. Since rational expectations is such a crucial assumption, 5 / it would be most useful to have some direct tests of its validity. Unfortunately this behavioral hypothesis is seldom tested in isolation. Most applied econometric work incorporating the rational expectations hypothesis only permits the testing of composite hypotheses: natural rate of unemployment plus rational expectations, term structure of interest rates plus rational expectations, the 
market model of asset pricing plus rational expectations, international interest parity plus rational expectations, etc. Survey data, such as the Livingston price index, while subject to all the problems associated with measuring unobservables through questionnaires, provide direct test of such rational expectations Implications as the error orthogonality property (see Brown and Maital [1979]). They have not been exploited to their full extent. The Principle of Pollcy-Dependent Structural Parameters

- The behavior of private agents depends in many ways on estimates of imperfectly observed past and present variables and on expectations of future variables. If changes in public sector behavior alter these estimates and expectations, models that ignore these links from (anticipated) government behavior via private expectations to private behavior are misspecified. Such misspecification may lead to poor conditional forecast and to erroneous conclusions being drawn from policy evaluation using simulation methods.

The rational expectations approach offers a simple solution to the problem of the link between private sector behavior, private sector expectations and government behavior: the private sector is assumed to know the true structure of the model, including the parameters that describe government behavior. The lesson of the rational expectations view for macroeconomic and macroeconometric modeling is the requirement to solve simultaneously for the currently anticipated future value of an endogenous varlable and its future value calculated from the model that incorporates these anticipations of the future. Once this is done the models incorporate the response of the private sector to current and anticipated future government actions and fully respect the "principle of pollcy-dependent 
structural parameters." Policy simulation exercises that are Imune to the "Lucas Critique" can then be carried out.

IV. Inconsistency of Optimal Plans or the Rules of the Game

In a well-known paper Kydland and Prescott have argued that optimal control in rational expectations models is Impossible (Kydland and Prescott [1977]). In more recent statements, this argument has been weakened to the proposition that the search for optimal policies should be limited to a comparison of alternative fixed operating rules in order to select the one with the most attractive operating characteristics. The most plausible interpretation of their view is that in rational expectations models optimal policies are of the open-loop-type rather than of the closed-loop or feedback type. As stated before, an open-loop policy is a non-state dependent policy announced at some initial date which specifies the values of the policy instruments for all future time as a function of the information set at the initial date. Closed-loop or feedback policies make the values of the instruments at the current moment and in the future a possibly time-varying but known (as of the initial date) function of the current (respectively the future) states of the economy. These future states w1ll be random variables in a stochastic world. In conventional control theory, 1.e. control theory applied to causal models (defined below), open-loop and closed-loop policles are equivalent in deterministic games against nature, $1 . e .$, for single controller opti-mization problems under certainty. They are different in 2 or n-person noncooperative games, deterministic or stochastic, and in all stochastic models. In causal models, closed-loop policies are never dominated by open-loop policles from the point of view of a single controller. Kydland and Prescott's proposition is quite distinct from the New Classical 
proposition that only unanticipated (monetary) policy can have real effects. It applies with full force only if the anticipated future values of the policy instruments as well as innovations in the policy instruments affect the joint probability density functions of real variables.

According to Kydland and Prescott, in a dynamic game with foresight such as the model of an economy with rational optimizing private agents and a rational optimfing public sector, standard (stochastic) dynamic programming approaches to the derivation of optimal policles may be inappropriate. Optimal plans are Inconsistent and consistent plans, 1.e., those derived from dynamic programming, are suboptimal. Traditional consistent optimal control techniques do not allow for the fmpact of future policy measures on the current state through the changes in current behavior induced by anticipation of these future policy measures. According to Prescott [1977] a consistent policy or plan is a sequence of rules, one for each period, which specifies policy actions contingent on the state of the world in that period. Each such rule has the property of being optimal given the subsequent elements in the sequence. In dynamic games with optimizing agents endowed with rational expectations, the optimal plan in subsequent periods may not be the continuation of the first-period optimal plan over the remalnder of the planning perlod: the optimal plan is not consistent. An attempt at a systematic discussion of the important subject of optimal control in rational expectations models follows. 
IV.a.Optimal Control in Causal and Noncausal Models

Traditional optimal control techniques for dynamic models are presented most thoroughly in Chow [1975]. Applications to financial programming incorporating estimated versions of the Polak model for the Philippines can be found In Wong and Pettersen [1976] and Basu [1979]. In order to be appl1cable to problems encountered in modern macroeconomic analysis, the traditional approach must be extended in two directions. The first extension is to allow for many independent controllers or "players" with distinct and possibly conflicting objectives. Each player is aware of and responds to the current and anticipated future actions of the other players. Thus, instead of modeling a single controller playing a game against "nature," we need the approach of multiplayer dynamic game theory or differential games. .

The second extension is to develop optimization techniques for noncausal models. Both single-player and many-player solution techniques need to be developed. The distinction between causal and noncausal models is a familiar one in the control engineering 1iterature. In a causal system the state of the system at time $\tau, y_{\tau}$, is completely determined once a past state $y_{t-1}, 1=1,2, \ldots$ is given together with the entire sequence of values of the forcing variables or inputs, $v_{t}$, between $\tau-1+1$ and $\tau, 1 . e^{\text {, }}$ $\left(v_{\tau-1+1}, v_{\tau-1+2}, \ldots, v_{\tau-1}, v_{\tau}\right)$. If the system is stable, the Influence of the inftial state w11l ultimately vanish and the current state will be a function only of all past and present inputs. Inputs are the exogenous varlables, the Instruments and the random disturbances. Causal system are solved forward in time from a given Initial condition. Noncausal systems 
are systems for which it is not sufficient for determining $y_{\tau}$ to know an inftial condition $y_{\tau-1}, i>0$, and the values of the forcing variables or Inputs between $\tau-1$ and $\tau$ (Inclusive). In addition, knowledge of (expected) future inputs $v_{\tau+j}, j=1,2, \ldots$, is required. Noncausal moiels have been argued to arise frequently in the context of rational expectations models, although some rational expectations models, in particular those incorporating only expectations of the present or the past, have been solved as causal models. Figure 1 outlines the state of the arts in optimal control with one or many players in causal and noncausal models. 


\section{Figure 1}

\section{Causal Models}

1. Single player

a. Deterministic

B. Stochastic

2. Many players

a. Cooperative

a) Deterministic

B) Stochastic -

b. Noncooperative
- Nash (memory- less).
Stochastic and non- stochastic

- Stacke1berg (memoryless) Stochastic and nonstochastic
Open-loop and closed-loop equivalent. Both optimal.

Closed-1oop superior to open loop.

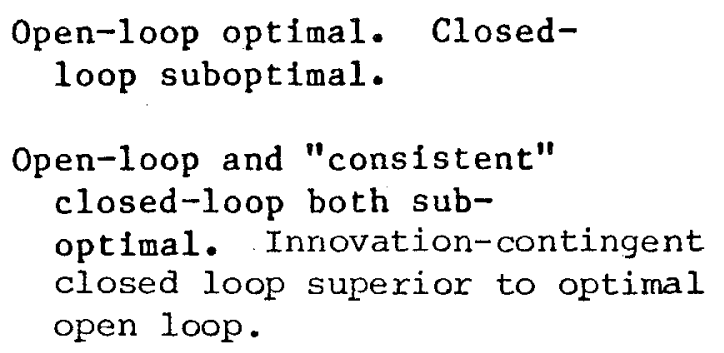

Noncausal Models 


\section{IV.b.Dynamic Games in Causal Models}

For simplicfty only linear discrete time dynamic systems are considered. All finfte order stochastic difference equation systems with disturbances represented by finite order arima processes can be written as a first order autoregressive stochastic difference equation system with a zero-mean serially independent disturbance vector (Chow [1975]) as in (1).

1. $y_{t}=A_{t} y_{t-1}+\sum_{j=1}^{N} C_{j t} x_{j t}+b_{t}+u_{t}$ $y_{t}$ is an $n \times 1$ vector of state varlables, $x_{j t}$ an $r_{j} x l$ vector of instruments controlled by the $j$ th player, $j=1, \ldots, N, b_{t}$ an $n \times l$ vector of exogenous variables and $u_{t}$ an $n \times 1$ vector of disturbances. $E\left(u_{t}\right)=0, E\left(u_{t} u_{t}^{\prime}\right)=\nabla$, $E\left(u_{t} u_{s}^{\prime}\right)=0$ for $t \neq s . A_{t}$ and $C_{j t}$ are known coefficient matrices. Given some inftial state $y_{0}=\vec{y}_{0}$, it is easily seen that the system given in (1) has a causal solution. By repeated substitution (1) can be written as in $\left.1^{\circ}\right)$. $y_{t}$ is a function only of past and current inputs.

$$
\begin{aligned}
1^{\prime} \cdot y_{t}= & \prod_{i=0}^{t-1} A_{t-1} y_{0}+u_{t}+\sum_{k=0}^{t-2} \underset{i=0}{I} A_{t-1} u_{t-k-1} \\
& +\sum_{j=1}^{N} C_{j t} x_{j t}+\sum_{k=0}^{t-2} \underset{i=0}{k} A_{t-1} \sum_{j=1}^{N} C_{j t-k-1} x_{j t-k-1} \\
& +b_{t}+\sum_{k=0}^{i} \underset{i=0}{K} A_{t-1} b_{t-k-1}
\end{aligned}
$$

Each player, 1, minimizes the following cost functional:

2. $W_{1}=E_{0}\left[\frac{1}{2} \sum_{t=1}^{T}\left(y_{t}-a_{1 t}\right)^{\prime} R_{1 t}\left(y_{t}-a_{1 t}\right)\right] \quad 1=1, \ldots, N$.

$\mathrm{K}_{1 \mathrm{t}}$ is a known, symmetric positive semidefinite matrix. $\mathrm{E}_{0}$ the mathematical expectation operator conditional on the information available at $t=0$. 
The Nash equilibrium

The class of supergame strategies considered ts of the sort

$$
s_{1}=\left(x_{11}\left(y_{0}\right), \ldots, x_{1 T}\left(y_{T-1}\right)\right] \quad 1=1, \ldots, N \text {. }
$$

They are closed-loop, no-memory strategles. $\left\{x_{1} \frac{k}{3} \ldots, x\right\}$ is a non-cooperative equilibrium strategy if $w_{1}\left(x_{1}, \ldots, x_{1}, \ldots, x_{\mathbb{N}}\right) \leq w_{1}\left(x_{1}, \ldots, x_{1}, \ldots, x_{\hbar}\right)$.

This Nash-solution is a (non-cooperative) equilibrium because no player can improve his welfare by unilaterally changing his strategy.

The Nash equilibrium strategies are given in Proposition 1, which is a generalization of De Bruyne [1979].

\section{Proposition 1}

The unique non-cooperative Nash-Equilibrium strategies for player $1=1, \ldots, N$ and for $t=1, \ldots, T$ are given by

3a. $x_{i t}=G_{1 t} y_{t-1}+g_{i t}$

3b. $G_{i t}=-\left[C_{i t}^{\cdot} B_{i t} C_{i t}\right]^{-1} C_{i t}^{0} H_{1 t}\left[A_{t}+\sum_{\substack{j=1 \\ j \neq 1}}^{N} C_{j t} G_{j t}\right]$

3c. $g_{i t}=-\left[C_{i t}{ }^{\prime} H_{i t} C_{i t}\right]^{-1} c_{i t}^{e}\left[H_{i t}\left(\sum_{\substack{j=1 \\ j \neq 1}}^{N} c_{j t} g_{j t}+b t\right)-h_{i t}\right]$.

3d. $H_{1 t-1}=R_{1 t-1}+\left(A_{t}^{\prime}+\sum_{j=1}^{N} G_{j t}^{\prime} C_{j t}^{\circ}\right) B_{1 t}\left(A_{t}+\sum_{k=1}^{N} C_{k t} G_{k t}\right)$ $j \neq 1$

3e. $h_{i t-1}=R_{i t-1} a_{1 t-1}-\left(A_{t} \cdot+\sum_{\substack{j=1 \\ j \neq 1}}^{N} G_{j t}^{\prime} C_{j t}^{\prime}\right)\left[H_{i t}\left(b_{t}+\sum_{k=1}^{N} c_{k t} g_{k t}\right)-h_{1 t}\right]$

3f. $\mathrm{H}_{1 T}=\mathrm{K}_{1 T}$

$3 g \cdot h_{1 T}=k_{1 T} a_{1 T}$ 
This solution has a number of finteresting features. First, as one would expect in a non-cooperative game, each player's optimal strategy (represented by his $G_{i t}$ and $8_{i t}$ matrices) depends on and is determined simultaneously with the optimal strategies of all other players. Second, the solution to the single player "game against nature", the subject of the traditional optimal control literature, is the special case of equations $3 a-3 g$ when $N=1$. Third, while the model is causal, the solution functions in perod $t$ are a function of the solution functions in all future periods, $t+1, \ldots, T$. This is an implication of the Principle of Optimality of Dynamic Programing applied to differential games. An optimal strategy for the ith player has the property that, whatever the inftial state and dectsion are, the remaining decisions must constitute an optimal strategy for the ith player with regard to the state resulting from the first decision, allowing for the strategies pursued by the other players. The privately optimal strategies are consistent, in the sense of Kydland and Prescott, and vice versa. Finally, the individually optimal noncooperative solution is almost always socially suboptimal, in the sense that it belongs to the Pareto Optimal set "If and only if the cost functional $\left(w_{1}\right)$ of any one player is not Influenced, directly or Indirectly, through the system of difference equations, by the controls pursued by the other players." (De Bruyne [1979, p. 249]). That amounts to saying that the non-cooperative closed-loop memoryless Nash strategles are Pareto Optimal if and only if there is no conflict of interest, $1 . e$. , no real game. 
A strategy $N$-tuple $\widehat{x}=\left\{\hat{x}_{1}, \ldots \hat{x}_{N}\right\}$ belongs to the Pareto Optimal set 1.f.f. there exists no N-tuple of controls $\tilde{x}$ such that $W_{1}(\tilde{x}) \leq W_{1}(\tilde{x})$ for all 1 and $w_{1}(\tilde{x})<w_{1}(\widehat{x})$ for some 1 . (De Brugne [1979, p. 247]). The elements of the Pareto Optimal set can be found by solving the following optimization problem:

4. $\quad \mathrm{x}_{1}, \ldots \mathrm{x}_{\mathrm{N}} \sum_{i=1}^{N} \mu_{1} \mathrm{w}_{1}$

subject to (1), with $\sum_{1=1}^{N} \mu_{1}=1$ and $\mu_{1}>0,1=1, \ldots N$.

The solution to this standard optimal control problem is

5a. $x_{\text {it }}=\tilde{G}_{\text {it }} y_{t-1}+\tilde{g}_{1 t} \quad 1=1, \ldots, N ; t=1, \ldots, T$

5b. $\tilde{G}_{i t}=\left(C_{i t} \cdot \tilde{H}_{i t} C_{i t}\right)^{-1} c_{i t}^{\prime} \tilde{H}_{i t}\left(A_{t}+\sum_{\substack{j=1 \\ j \neq 1}}^{N} c_{j t} \tilde{G}_{j t}\right)$

5c. $\tilde{g}_{i t}=-\left(c_{i t} \cdot \tilde{H}_{i t} c_{i t}\right)^{-1} c_{i t}^{\prime}\left[\tilde{H}_{i t}\left(\underset{\substack{j=1 \\ j \neq 1}}{\sum} c_{j t}^{N} \tilde{z}_{j t}+b_{t}\right)-\tilde{h}_{i t}\right]$

5d. $\tilde{H}_{i t-1}=\sum_{j=1}^{N} \mu_{j} K_{j t-1}+A_{t} \cdot \tilde{H}_{i t}\left(A_{t}+\sum_{j=1}^{N} c_{j t} \tilde{G}_{j t}\right)$

se. $\tilde{h}_{i t-1}=\sum_{j=1}^{N} \mu_{j} R_{j t-1} a_{j t-1}-A_{t} \cdot\left[\tilde{H}_{1 t}\left(b_{t}+\sum_{j=1}^{N} c_{j t} \tilde{g}_{j t}\right)-\tilde{h}_{1 t}\right]$

5f. $\tilde{H}_{i T}=\sum_{j=1}^{N} \mu_{j} K_{j T}$

5g. $\quad \tilde{h}_{1 T}=\underset{j=1}{\Sigma} \mu_{j} K_{j T^{a}} T$

Note that the $\tilde{\mathrm{H}}_{1 \mathrm{t}}$ and $\tilde{\mathrm{h}}_{1 \mathrm{t}}$ are 1 dentical for all agents. 
Comparing the Nash-equilibrium solution $(3 a-3 g)$ and the Pareto Optimal solution $(5 a-5 g)$, we note that the Nash-equilibrium strategy belongs to the Pareto Optimal set 1.f.f. there exists a strictly positive vector $\left(\mu_{1}, \ldots, \mu_{N}\right)$ such that for all $i$ and for all $t,(6 a)$ and (6b) hold.

$$
\text { 6a. } \begin{aligned}
\sum_{k=1}^{N} \mu_{k} K_{k t-1}+A_{t} \cdot \tilde{H}_{1 t}\left(A_{t}+\sum_{k=1}^{N} C_{k t} \bar{G}_{k t}\right) \\
=K_{1 t-1}+A_{t} \cdot H_{i t}\left(A_{t}+\sum_{k=1}^{N} C_{k t} G_{k t}\right)+\sum_{\substack{j=1 \\
j \neq 1}}^{N} G_{j t}^{\prime} C_{j t} H_{1 t}\left(A_{t}+\underset{k=1}{\sum} C_{k t} G_{k t}\right)
\end{aligned}
$$

and

6b. $\sum_{k=1}^{N} \mu_{k} R_{k t-1} a_{k t-1}-A_{t} \cdot\left[\tilde{H}_{1 t}\left(b_{t}+\sum_{k=1}^{N} c_{k t} \tilde{g}_{k t}\right)-\tilde{h}_{1 t}\right]$

$$
\begin{aligned}
& =\mathrm{k}_{1 t-1} a_{1 t-1}-A_{t} \cdot\left[\mathrm{H}_{1 t}\left(b_{t}+\sum_{k=1}^{N} c_{k t} g_{k t}\right)-h_{1 t}\right] \\
& -\sum_{\substack{j=1 \\
j \neq 1}}^{N} G_{j t}^{\prime} \dot{C}_{j t}^{\prime}\left[H_{1 t}\left(b_{t}+\sum_{k=1}^{N} c_{k} g_{k t}\right)-h_{1 t}\right]
\end{aligned}
$$

By backward Induction from $t=T+1$ (6a) and (6b) imply that for the Nash equilibrium to be Pareto Optimal we need: ㄱ/

$$
R_{1 t}=\sum_{k=1}^{N} \mu_{k} R_{k t-1}
$$

$$
a_{1 t-1}=\sum_{k=1}^{N} \mu_{k} a_{k t-1}
$$

or

7a. $K_{1 t}=\sum_{\substack{k=1 \\ k \neq 1}}^{N} \frac{\mu_{k}}{1-\mu_{1}} k_{k t} \quad$ for all 1 and $t$ 
7b. $a_{1 t}=\sum_{\substack{k=1 \\ k \neq 1}}^{N} \frac{\mu_{k}}{1-\mu_{1}} a_{k t} \quad$ for all 1 and $t$

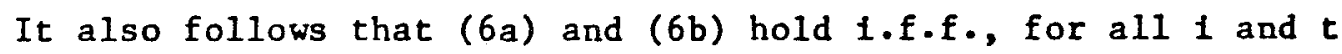

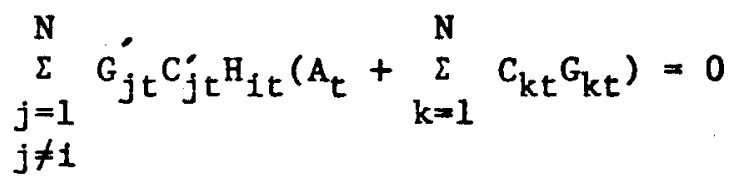

and

$$
\underbrace{N}_{\substack{j=1 \\ j \neq 1}} G_{j t}^{\prime} C_{j t}^{\prime}\left[H_{1 t}\left(b_{t}+\sum_{k=1}^{N} C_{k t} g_{k t}\right)-h_{1 t}\right]=0
$$

This in turn requires

8a. $\sum_{\substack{j=1 \\ j \neq i}}^{N} G_{j t}^{\prime} C_{j t}^{\prime} B_{i t}=0$

and

8b. $\sum_{\substack{j=1 \\ j \neq i}}^{N} G_{j t} c_{j t}^{\cdot} h_{i t}=0 \quad$ for all 1 and $t$

\section{Proposition 2}

The non-cooperative Nash equiltbrium strategies generate a Pareto Optimal solution 1.f.f. (a) there is no "conflict in tastes" and (b) there 1s no "instrument Interdependence."

The absence of conflict of interest through the players' cost functionals is represented by conditions (7a) and (7b): each player's cost functional is a positive linear combination of the cost functionals of all other players. Identical tastes are an example, with $R_{1 t}=R_{j t}=R_{t}$, $a_{1 t}$ $=a_{j t}=a_{t}$ and $\mu_{j}=\mu_{1}=N^{-1}$ for all $1, j$ and $t$. Equations (8a) and (8b) imply that for each player the optimal closed-loop strategy w.r.t. the other 
players ${ }^{\circ}$ actions is the same as the optimal open-loop strategy w.r.t. the other players' actions. On balance, the optimal response of the ith player to the strategies of each of the other players is to ignore the other players' strategies. For all practical purposes, the possibility that the non-cooperative Nash solution is Pareto Optimal can be excluded. Proposition 2 is an 1 llustration of the general proposition that noncooperative Nash equilibria do not as a rule lie on the contract curve and therefore are socially suboptimal. If all players were to cooperate and if side-payments were possible, it would in general be possible to achieve a lower minimum expected cost for each player, as compared with the noncooperative equilibrium. To recognize this is not to dismiss the Nash equilibrium as inappropriate. It is inconststent only with collective or group rationality, not with decentralized individual rationality. Which kind of game, cooperative or noncooperative is more appropriate as a description of certain aspects of economic life, is an empirical issue. Sometimes the nature of pre-play negotiation is such that the players can form a coalition to discuss and coordinate strategies before the game is played, and make binding, enforceable agreements on strategy. Contract law is an example of a set of collectively imposed and enforced restrictions on individual freedom of choice. Many real-ilfe situations exist in which players cannot coordinate their strategies to play a cooperative game. The Stackelberg equilibrium

The Nash equilibrium strategles of equations $(3 a)-(3 g)$, may be viewed as too "symetric" to adequately model the interrelationship between a large 
government and a multitude of small prive private agents. A stackelberg equilibrium with the government playing the "leader"s" part and the private sector acting as "followers" may be closer to reality. The leader takes the actions of the followers as given. The followers take each other's actions as given but incorporate the response of the leader to the state of the system into their optimal strategies. Proposition 3 states the optimal closed-loop memoryless strategies of the leader (player 1), and the followers ( $p$ layers 2,.., N). The description of the system (equation 1) and of the cost functional (equation 2) is the same as before.

\section{$\underline{\text { Proposition } 3}$}

The unique noncooperative Stackelberg equilibrium strategies for the leader, player 1, and for the followers, players $2, \ldots, N$, for periods $t=1, \ldots, T$ are given by:

9a. $x_{1 t}=\hat{G}_{1 t} y_{t-1}+\hat{g}_{1 t}$

9b. $\hat{G}_{1 t}=-\left(c_{1 t} \cdot \hat{\mathrm{B}}_{1 t} \mathrm{c}_{1 t}\right)^{-1} \mathrm{c}_{1 t} \cdot \hat{\mathrm{B}}_{1 t}\left(A_{t}+\sum_{j=2}^{N} c_{j t} \hat{G}_{j t}\right)$

9c. $\hat{\mathrm{s}}_{1 t}=-\left(\mathrm{C}_{1 t} \cdot \hat{\mathrm{B}}_{1 \mathrm{t}} \mathrm{C}_{1 t}\right)^{-1} \mathrm{C}_{1 t} \cdot\left[\hat{\mathrm{B}}_{1 t}\left(\underset{j=2}{\mathrm{~N}} \mathrm{c}_{j t} \hat{\mathrm{B}}_{j t}+\mathrm{b}_{t}\right)-\hat{\mathrm{h}}_{1 t}\right]$

9d. $\hat{\mathrm{H}}_{1 t-1}=\mathrm{K}_{1 t-1}+\mathrm{A}_{t} \cdot \hat{\mathrm{B}}_{1 t}\left(\mathrm{~A}_{t}+\sum_{j=1}^{N} \mathrm{c}_{j t} \hat{\mathrm{G}}_{j t}\right)$

9e. $\hat{h}_{1 t-1}=k_{1 t-1} a_{1 t-1}-A_{t} \cdot\left[\hat{B}_{1 t}\left(b_{t}+\sum_{j=1}^{N} c_{j t} \hat{8}_{j t}\right)-\hat{h}_{1 t}\right]$

9f. $\hat{\mathrm{H}}_{1 \mathrm{~T}}=\mathrm{R}_{1 \mathrm{~T}}$

$9 g \cdot \quad \hat{h}_{1 T}=k_{1 T} a_{1 T}$

$9 a^{\prime} \cdot x_{i t}=\hat{G}_{1 t} y_{t-1}+\widehat{B}_{1 t} \quad \quad 1=2, \ldots, N$ 


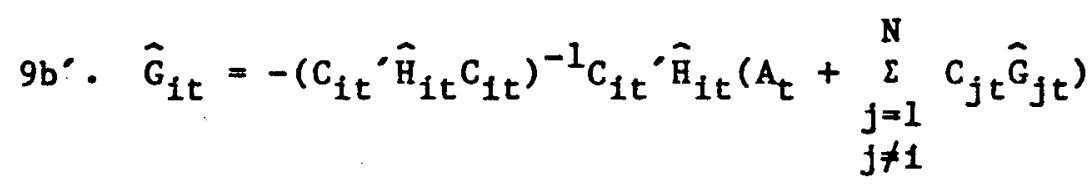

$9 c^{\prime} \cdot g_{1 t}=-\left(C_{1 t} \cdot \hat{B}_{1 t} c_{1 t}\right)^{-1} c_{1 t} \cdot\left[\hat{B}_{1 t}\left(\underset{\substack{j=1 \\ j \neq 1}}{\sum} c_{j t} \hat{g}_{j t}+b_{t}\right)-\hat{h}_{1 t}\right]$

$9 d^{\prime} \cdot \hat{\mathrm{H}}_{1 t-1}=R_{1 t-1}+\left(A_{t} \cdot+\hat{G}_{1 t}^{\prime} c_{1 t}{ }^{\prime}\right) \hat{\mathrm{H}}_{1 t}\left(A_{t}+\sum_{j=1}^{N} c_{j t} \hat{G}_{j t}\right)$

$9 e^{\prime} \ldots \hat{h}_{1 t-1}=k_{1 t-1} a_{1 t-1}-\left(A_{t}^{\prime}+\hat{G}_{1 t}{ }^{\prime} c_{1 t}{ }^{\prime}\right)\left[\hat{H}_{1 t}\left(b_{t}+\sum_{j=1}^{N} c_{j t} \hat{g}_{j t}\right)-\hat{h}_{1 t}\right]$

$9 f^{\circ} \cdot \hat{H}_{1 T}=K_{1 T}$

$9 g^{\circ} \cdot \tilde{h}_{1 T}=K_{1 T^{a}}{ }_{1 T}$

Proof: See Buiter and Eaton [1979].

The asymetry between the leader's optimal strategy and the followers' optimal strategies is evident from a comparison of (9d) and (9e) with (9d ) and $\left(9 e^{\prime}\right)$. By contrasting the cooperative solution, equations $5 a-5 g$, with the Stackelberg solution, we note that the Stackelberg solution too will not be Pareto Optimal, unless

$$
R_{1 t}=\sum_{\substack{k=1 \\ k \neq 1}}^{N} \frac{\mu_{k}}{1-\mu_{1}} R_{k t}, a_{1 t}=\sum_{\substack{k=1 \\ k \neq 1}}^{N} \frac{\mu_{k}}{1-\mu_{1}} a_{k t}
$$

and $\bar{G}_{1 t}{ }^{\prime} C_{1 t} \cdot \hat{B}_{1 t}=0$ and $G_{1 t}^{\prime} C_{1 t} \cdot \hat{h}_{1 t}=0$ for all 1 and $t$. IV, c. Rational expectations in causal models

The analysis developed so far can be applled unchanged when rational expectations of the state vector are added to equation (1) If these expectations are past expectations of the current state vector or of past state vectors. I.e., terms like $E\left(y_{t-1} \mid I_{t-1-j}\right), 1 \geq 0 ; f \geq 1$ can be added without 
additional complications. $I_{t}$ is the Information set available in period $t . \underline{8} /$ Consider the following model:

10. $y_{t}=A_{t} y_{t-1}+\sum_{j=1}^{N} B_{j t} E\left(y_{t} \mid I_{t-1}\right)+\sum_{j=1}^{N} C_{j t} x_{j t}+b_{t}+u_{t}$

Assuming that the relevant inverse exists, that $y_{t-1}$ is an element of $I_{t-1}$ and that $x_{j t}$ is known in period $t-1$ for all $j$, the expectation term can be substitubed out and (10) becomes:

$$
\begin{aligned}
10^{\circ} . y_{t}= & {\left[I-\sum_{j=1}^{N} B_{j t}\right]^{-1} A_{t} y_{t-1}+\left[I-\sum_{j-1}^{N} B_{j t}\right]^{-1} \sum_{k=1}^{N} C_{j t} x_{j t} } \\
& +\left[I-\sum_{j=1}^{N} B_{j t}\right]^{-1} b_{t}+u_{t}
\end{aligned}
$$

This is isomorphic to equation (1) and is therefore amenable to the same optimization approach. When expectations of the future enter the model the noncausal solution of a model is often viewed as the appropriate one and considerable complications arise.

IV .d. Noncausal models

It is probably better to talk of causal and noncausal solutions to models than of causal and noncausal models. Every dynamic model has a causal (or "backward-looking") and a noncausal (or "forward-looking") solution. This is most easily demonstrated with the scalar linear differential equation model of equation (11).

11. $\dot{y}+q(t) y=g(t)$

The causal or backward-looking solution $y_{b}(t)$ of (11) is

12a. $y_{b}(t)=\left[e^{\int_{-\infty}^{t} q(z) d z}\right]^{-1}\left[\int_{-\infty}^{t e^{\int_{-\infty}^{s} q(z) d z}} \cdot g(s) d s+c_{1}\right]$ 
The noncausal or forward-looking solution $y_{f}(t)$ of (11) is

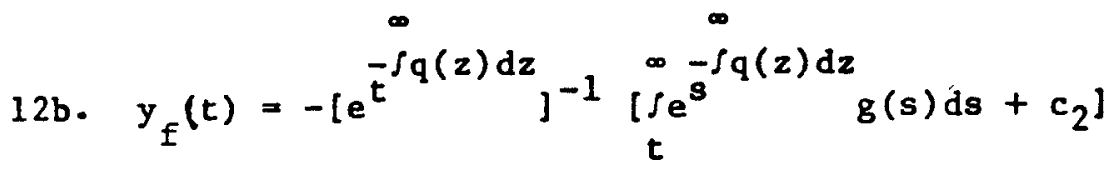

$c_{1}$ and $c_{2}$ are arbitrary constants.

Indeed, as Blanchard [1978] has pointed out, any linear combination of the backward and the forward solutions with weights that sum to unity, such as $y_{M}$ in (13), is also a solution to (11).

13. $y_{M}(t)=\alpha y_{b}(t)+(1-\alpha) y_{f}(t)$

The mathematics are quite silent on which one of the continuum of solutions given in (13) to pick. Economic theory must narrow down the possible range. If $y(t)$ is an asset price determined in an efficlent market the noncausal solution (12b) may be the natural one. In terms of equation (11), momentary equilibrium is represented by an equation relating the asset price, $y$, its (actual and expected) rate of change, $\dot{y}$ and an exogenous variable or policy instrument $g(t)$. By specifying the expected (= actual) rate of change of $y$ as the right-side derivative of $y(t)$, discontinuous jumps in $y$ at a polnt in time are permitted. To determine the (expected) rate of change of $y$ at $t$ we must determine the entire future path of $y$ from $t$ till Kingdom Come. This noncausal solution was proposed by Sargent and Wallace [1973] for a money-and-growth model. If the price were determined in an Inefficient 'market and 18 viewed as predetermined at any given instant, the causal solution is the appropriate one.

Note that if the model in (11) has a stable backward-looking solution for a constant path of the forcing function $g(s)$ its forward-looking solution will be unstable and vice versa. This is especially clear in the discrete time linear model of equation (1) to which we now return. For simplicity, 
we assume $A_{j}$ and $C_{j t}$ to be time-invariant, i.e., $A_{t}=A$ and $C_{j t}=C_{j}$ for all t. We also assume $A$ to be invertible. The model is given in $\left(1^{\prime}\right)$ : $I^{\prime} \cdot y_{t}=A y_{t-1}+\sum_{j=1}^{N} C_{j} x_{j t}+b_{t}+u_{t}$

The causal solution is:

14a. $y_{t}=A^{T} y_{t-T}+\sum_{k=0}^{T-1} A^{k} \sum_{j=1}^{N} c_{j} x_{j t-k}+\sum_{k=0}^{T-1} A^{k} b_{t-k}+\underset{k=0}{\sum_{k} A^{k} u_{t-k}}$

The noncausal solution is:

14b. $y_{t}=\left(A^{-1}\right)^{T} y_{t+T}-\sum_{k=1}^{T}\left(A^{-1}\right)^{k} \sum_{j=1}^{N} C_{j} x_{j t+k}-\sum_{k=1}^{T}\left(A^{-1}\right)^{k_{b}} b_{t+k}-\underset{k=1}{T}\left(A^{-1}\right)^{k} u_{t+k}$ Consider the noncausal solution. If the characteristic roots of A are $\lambda_{1}, 1=1, \ldots n$, the characteristic roots of $A^{-1}$ are given by $\mu_{1}=\frac{1}{\lambda_{1}}$. Thus, if the causal solution (14a) is stable for constant values of the forcing variables (the characteristic roots of $\mathrm{A}$ all have modulus $<1$ ), the noncausal solution (14b) is unstable and vice versa. If $A$ is stable in (14a) the term $A^{T} y_{t-1}$ will vanish as $T+\infty$ if $\lim _{T \rightarrow \infty} y_{t-T}$ is bounded. If $A^{-1}$ is stable in (14b) the term $\left(A^{-1}\right)^{T} y_{t+T}$ will vanish as $T \rightarrow \infty$ if $\lim _{T \rightarrow \infty} y_{t+T}$ is bounded. Both these conditions appear reasonable if $\sum_{i=0}^{\infty} A^{k}\left(\sum_{j=1}^{N} C_{j} x_{j t-k}+b_{t-k}+u_{t-k}\right)$, resp. $\sum_{k=1}^{\infty}\left(A^{-1}\right) k\left(\sum_{j=1}^{N} C_{j} x_{j t+k}+b_{t+k}+u_{t+k}\right)$ are bounded. 
More generally, economic theory may suggest that the noncausal solution be chosen for only a subset of the elements of the state vector, with the causal solution being chosen for the remaining elements of the state vector. $9 /$ A two-dimensional example of mixed causal-noncausal model is Sargent [1976]. A perfect foresight money-and-growth model reduces to a system of two simultaneous first-order difference equations in the price level, $y_{1 t}$, and the capital stock, $y_{2 t} \cdot$ The price level, determined in an efficient market, is the noncausal variable, the capital stock--a truly predetermined variable if ever there was one-is the causal variable. ..

The system is summarized in (15). $z_{1 t}, 1=1,2$, are the forcing functions, 1.e., the exogenous variables, policy instruments or random disturbances. 15. $\left[\begin{array}{l}y_{1, t} \\ y_{2, t}\end{array}\right]=\left[\begin{array}{ll}a_{11} & a_{12} \\ a_{21} & a_{22}\end{array}\right]\left[\begin{array}{l}y_{1, t-1} \\ y_{2, t-1}\end{array}\right]+\left[\begin{array}{l}z_{1, t} \\ z_{2, t}\end{array}\right]$

We can find the forward-looking solution for $y_{1, t}$ as a function of current, and future values of $y_{2, t}$, future values of the forcing variable $z_{1, t}$ and a terminal condition for $y_{1, t}$. 16a. $y_{1, t}=-a_{12} \sum_{j=1}^{M}\left(\frac{1}{a_{11}}\right)^{J_{y_{2}}} y_{2, t-1+j}-\sum_{j=1}^{M}\left(\frac{1}{a_{11}}\right)^{j_{2}} z_{1, t+j}+\left(\frac{1}{a_{11}}\right)^{M_{y_{1}}}, t+M$ We can also find the back-ward looking solution for $y_{2}, t$ as a function of past values of $y_{1, t}$, current and past values of the forcing variable $z_{2, t}$ and an Inftial condition for $y_{2, t}$ 
16b. $y_{2, t}=a_{21} \sum_{k=0}^{T}\left(a_{22}\right)^{k_{y_{1, t-k-1}}}+\sum_{k=0}^{T}\left(a_{22}\right)^{k_{z_{2}}}{ }_{2, t-k}+\left(a_{22}\right)^{T_{y_{2, t}}}$.

(16a) and (16b) must be solved simultaneously, a computationally dreary but feasible task if $M$ and $T$ and not too large. E.g., for $y_{2 t}$ we have:

$$
\text { 17. } \begin{aligned}
y_{2, t}= & -a_{21} a_{12} \sum_{k=0}^{T}\left(a_{22}\right)^{k} \sum_{j=1}^{M}\left(\frac{1}{a_{11}}\right)^{j_{y_{2}}}, t-k+j-2 \\
& -a_{21} \sum_{k=0}^{T}\left(a_{22}\right)^{k} \sum_{j=1}^{M}\left(\frac{1}{a_{11}}\right)^{j_{z}} z_{1, t-k+j-1} \\
& +\sum_{k=0}^{T}\left(a_{22}\right)^{k} z_{2, t-k}+a_{21} \sum_{k=0}^{T}\left(a_{22}\right)^{k}\left(\frac{1}{a_{11}}\right)^{M} y_{1, t-k-1+M} \\
& +\left(a_{22}\right)^{T} y_{2, t-T}
\end{aligned}
$$

Equation (17) can now be substituted into (16a) to give the solution for $y_{1, t}$. Equation (17), however, still expresses $y_{2, t}$, the causal varlable, as a function of its own past and future values, the past and future values of the forcing varfable $z_{1, t}$, the current and past values of the forcing variable $z_{2, t}$, a terminal condition for $y_{1, t}$ and an initial condition for $y_{2, t}$. This is hardly the standard difference equation that appears in conventional policy simulation and optimization models. If $M$ is finite we can solve equation (17) for $y_{2, t+M-2}$, the "last" value of $y_{2}$, as a function of Its own past values, past values of the forcing variable $z_{2}$, an inftial condition for $y_{2}$, a terminal condition for $y_{1}$, current and past values of the forcing varlable $z_{1}$ and 1 ts future value in pertod $t+M-1$. The presence. of this future value of the forcing vartable means that it is 1mpossible to reduce the model to the standard state-space form to which the optimization techniques for causal models can be applied. Furthermore, there is no need for $M$ to be finite. 
Note that this problem has nothing to do with formal game-theoretic interdependence between decentralized players. The model of equation (15) could represent a single active player (the one controlling $z_{1, t}$ and $z_{2, t}$ ' controlling a forward-looking but passive system. We demonstrated in the previous section that differential games can be handled satisfactorily in causal models. In principle, the problems of optimization in noncausal models highlighted by kydland and Prescott are also independent of the assimption of rational expectations. This needs to be qualified imnediately, however, by noting that models in which the current value of the state vector, $y_{t}$, depends on rational expectations of future values of $y_{t}$, i.e., on $t\left(y_{t+i} \mid I_{t-j}\right), i>0, j \geq 0$, are the most common examples of noncausal models in economics.

It is important to note the difference between the appearance of future values of the forcing variables in the final form of noncausal models (equations (14b) and (17) and the simultaneous determination of the current optimal values of the policy rules and their future optimal values in causal models (equations $(3 a-3 g),(5 a-5 g)$, or $9 a-9 g)$. The recursive nature of the feedback solutions to optimal control problems in causal models is a direct consequence of the Principle of Optimality which in turn can virtually be viewed as the definition of rationality in dynamic causal models. The future exogenous variables, instruments and disturbances that appear in the final form of noncausal models are there quite independently of any optimizing behavior by the players. This dependence of the current state on future instrument values creates problems in optimization that are not yet fully resolved. 


\section{IV.e. Rational Expectations of Future Endogenous Variables and Noncausal Models}

The noncausal solutions to equation ( $\left.1^{\prime}\right)$ (given in (14b)) and to equation (15) (given in (17)) have a feature that makes them unlikely to qualify as solutions to economic models. In (14b) explictly and in (17) implicitly, the current value of the state vector depends on the actual, realized values of future stochastic disturbances. While the mathematics is willing, economic common sense does not accept the proposition that future random variables (as opposed to current and past estimates or distribution functions of future random variables) can influence the current state. Noncausal models that arise in economic applications will have known future exogenous variables and estimates of future random variables as determinants of the current state vector. A very simple example of such a model is given in (18). The $u_{t}$ are white noise disturbances. 18. $y_{t}=A y_{t-1}+B E\left(y_{t+1} \mid I_{t}\right)+C x_{t}+b_{t}+u_{t}$

The noncausal or backward solution of (18) can be found by recursive substitution. E.g., after two steps we have

$$
\begin{aligned}
y_{t}= & \left\{I-B[I-B A]^{-1} A\right\}^{-1} \\
& {\left[\begin{array}{l}
A y_{t-1}+C x_{t}+b_{t}+u_{t}+B[I-B A]^{-1}\left(B C E\left(x_{t+2} \mid I_{t}\right)+C E\left(x_{t+1} \mid I_{t}\right)+B b_{t+2}+\right. \\
\left.\left.b_{t+1}+B^{2} E\left(y_{t+3} \mid I_{t}\right)\right)\right]
\end{array}\right.}
\end{aligned}
$$

The general solution is of the form:

$$
\text { 19. } \begin{aligned}
y_{t}= & \tilde{A}_{t}\left[A y_{t-1}+C x_{t}+b_{t}+u_{t}\right]+\sum_{i=t+1}^{\infty} \tilde{C}_{t, i}\left[C E\left(x_{i} \mid I_{t}\right)+b_{i}\right] \\
& +\lim _{N \rightarrow \infty} \tilde{B}_{t, N} E\left(y_{t+N} \mid I_{t}\right) 10 /
\end{aligned}
$$


The $\tilde{A}_{t}, \tilde{C}_{t, i}$ and $\tilde{B}_{t, N}$ are known, time-varying functions of the structural coefficient matrices $A, B$ and $C$.

The current value of $y$ depends on 1 ts own lagged value, on the current and expected future values of the policy instruments, on the current and future values of the known exogenous variables and on the terminal condition for the expectation process. In each period a new (and different) terminal condition for the expectation process can be chosen (Shiller [1978]). This non-uniqueness problem does not yet have a satisfactory solution.

However, there is nothing in the mathematics of rational expectations models, even if they involve expectations of future variables, that compels the selection of the noncausal solution to (18) given in (19).

A causal solution to (18) is found most easily by the method of undetermined coefficients. Assume there exists a solution to (18) of the form: 20a. $y_{t}=k_{t}+\underset{i=0}{i} \Pi_{i} u_{t-i}$ Here $k_{t}$ denotes a time-varying nonstochastic term and $\pi_{i}$ a set of constant coefficients.

Leading (20a) one period and taking the expectation conditional on $I_{t}$ we get:

20b. $E\left(y_{t+1} \mid I_{t}\right)=k_{t+1}+\sum_{i=1}^{\infty} \Pi_{i} u_{t+1-i}$

Substituting (20a) and (20b) into (18) and collecting terms yields

20c. $y_{t}=A k_{t-1}+B k_{t+1}+C x_{t}+b_{t}+\left(B \Pi_{1}+I\right) u_{t}+\sum_{i=0}^{\infty}\left(A \pi_{1}+B \Pi_{1+2}\right) u_{t-1-i}$

Equating coefficients between (20a) and (20c) we obtain:

20d. $k_{t}=A k_{t-1}+B k_{t+1}+C x_{t}+b_{t}$

20e. $\mathrm{I}_{0}=\mathrm{BI}_{1}+\mathrm{I}$ 
20f. $\pi_{i}=A \pi_{i-1}+B \pi_{i+1}, \quad i=1,2, \ldots$.

Next subtract $A y_{t-1}+B y_{t+1}$ from (20c) using (20a) and (20d, e and f).

This yields:

20g. $\quad y_{t}-A y_{t-1}-B y_{t+1}=C x_{t}+b_{t}+u_{t}$

If $B$ is invertible, $11 /$ this can be rewritten as:

20h. $y_{t}=B^{-1} y_{t-1}-B^{-1} A y_{t-2}-B^{-1} C x_{t-1}-B^{-1} b_{t-1}-B^{-1} u_{t-1}$

It is clear that $(20 \mathrm{~h})$ is a solution to (18), because from (20h) it follows

that $E\left(y_{t+1} \mid I_{t}\right)=y_{t+1}$. However, it is not the only solution. Another

causal solution to ( 18$)$ is given by $\left(20 \mathrm{~h}^{\circ}\right)$.

$20 h^{\prime} \cdot y_{t}=B^{-1} y_{t-1}-B^{-1} A y_{t-2}-B^{-1} C x_{t-1}-B^{-1} b_{t-1}-B^{-1} u_{t-1}+\psi_{t} u_{t}$

$\psi_{t}$ is an undetermined, possibly time-varying parameter. If $x_{t}$ is stochastic,

the current innovation in $x_{t}$ could also enter the causal solution,

again with an unknown coefficient.

$$
\begin{aligned}
20 h^{\prime \prime} . y_{t}= & B^{-1} y_{t-1}-B^{-1} A y_{t-2}-B^{-1} C x_{t-1}-B^{-1} b_{t-1}-B^{-1} u_{t-1} \\
& +\psi_{t} u_{t}+\phi_{t}\left(x_{t}-E\left(x_{t} \mid I_{t-1}\right)\right)
\end{aligned}
$$

The most general causal solution of (18) is

$20 h^{\prime \prime} \cdot y_{t}=B^{-1} y_{t-1}-B^{-1} A y_{t-2}-B^{-1} C x_{t-1}-B^{-1} b_{t-1}-B^{-1} u_{t-1}+\varepsilon_{t}$

$\varepsilon_{t}$ is a random disturbance whose only defining property is $E\left(\varepsilon_{t} \mid I_{t-1}\right)=0$

This random disturbance could contain not only such "fundamental" innovations as $u_{t}+C\left(x_{t}-E\left(x_{t} \mid I_{t-1}\right)\right)$, but also any "will-o-the-wisp" disturbance, absent from the structure of $(18)$, that has the property $E\left(\varepsilon_{t} \mid I_{t-1}\right)=0$, (see Taylor [1977]). This is the causal counterpart of the non-uniqueness problem in the noncausal solution of the model.

This multiplicity of solutions is worrying. It is not clear on general economic grounds which solution one should prefer. For concreteness I shall 
$h$ se the special case where $\psi_{t}=\phi_{t}=0$, i.e., the solution in (20h). The standard first order represention of (20h) is given in (21).

21. $\left[\begin{array}{l}y_{t} \\ y_{t-1} \\ x_{t} \\ b_{t} \\ u_{t}\end{array}\right]=\left[\begin{array}{ccccc}B^{-1} & -B^{-1} A-B^{-1} C-B^{-1} & -B^{-1} \\ I & 0 & 0 & 0 & 0 \\ 0 & 0 & 0 & 0 & 0 \\ 0 & 0 & 0 & 0 & 0 \\ 0 & 0 & 0 & 0 & 0\end{array}\right]\left[\begin{array}{l}y_{t-1} \\ y_{t-2} \\ x_{t-1} \\ b_{t-1} \\ u_{t-1}\end{array}\right]+\left[\begin{array}{l}0 \\ 0 \\ I \\ 0 \\ 0\end{array}\right]+\left[\begin{array}{l}x_{t} \\ 0 \\ 0 \\ b_{t} \\ 0 \\ 0 \\ 0 \\ 0 \\ u_{t}\end{array}\right]$

With an initial condition for the augmented state vector $\left[y_{t}, y_{t-1}, x_{t}\right.$, $\left.b_{t}, u_{t}\right]^{\circ}$ this inodel can be solved as an ordinary causal model and all the results on optinal control and differential games in causal models can be applied to it.

By exactly analogous reasoning, the causal solution to the system:

22. $y_{t}=A y_{t-1}+B E\left(y_{t+1} \mid I_{t-1}\right)+C x_{t}+b_{t}+u_{t}$ can be found to be, if $x_{t}$ is nonstochastic:

23a. $y_{t}=B^{-1} y_{t-1}-B^{-1} A y_{t-2}-B^{-1} C x_{t-1}-B^{-1} b_{t-1}+u_{t}+n_{t-1}$

Here $n_{t-1}$ is defined by $E\left(n_{t-1} \mid I_{t-2}\right)=0$.

If $x_{t}$ is stochastic, the causal solution is:

23b. $y_{t}=B^{-1} y_{t-1}-B^{-1} A y_{t-2}-B^{-1} C x_{t-1}-B^{-1} b_{t-1}+u_{t}+C\left(x_{t}-E\left(x_{t} \mid I_{t-1}\right)\right)$

$$
+n_{t-1}
$$

$\eta_{t-1}$ is defined as before.

The nonuniqueness problem vanishes only in the perfect foresight case:

$y_{t}=A y_{t-1}+B y_{t+1}+C x_{t}+b_{t}$

This can be written in causal form as:

$$
Y_{t}=B^{-1} y_{t-1}-B^{-1} A y_{t-2}-B^{-1} C x_{t-1}-B^{-1} b_{t-1}
$$

The first-order representation of this system is: 


$$
\left[\begin{array}{l}
y_{t} \\
y_{t-1} \\
x_{t} \\
b_{t}
\end{array}\right]=\left[\begin{array}{ccccc}
B^{-1} & -B^{-1} A-B^{-1} C-B^{-1} & -B^{-1} \\
I & 0 & 0 & 0 & 0 \\
0 & 0 & 0 & 0 & 0 \\
0 & 0 & 0 & 0 & 0
\end{array}\right]\left[\begin{array}{l}
y_{t-1} \\
y_{t-2} \\
x_{t-1} \\
b_{t-1}
\end{array}\right]+\left[\begin{array}{l}
0 \\
0 \\
I \\
0
\end{array}\right]+\left[\begin{array}{l}
x_{t} \\
0 \\
0 \\
b_{t}
\end{array}\right]
$$

Given an inftial condition for $\left(y_{t}, y_{t-1}, x_{t}, b_{t}\right)^{\prime}$ this can be solved in the standard manner.

An economic example of some intrinsic interest that fits the general description of equation (18) is a Cagan-type hyperinflation model with rational expectations. $m_{t}$ is the $l o g$ of the noninal stock of money, $p_{t}$ the $\log$ of the price level, $r_{t}$ the real interest rate and $y_{t}$ real output. Monetary equilibrium is given by:

24. $m_{t}-p_{t}=\gamma+\alpha\left(r_{t}+E\left(p_{t+1} \mid I_{t}\right)-p_{t}\right)+2 y_{t}+v_{t}$ Assuming that the classical dichotomy holds, $r_{t}$ and $y_{t}$ are exogenous and can be ignored in what follows. Thus (24) simplifies to:

$24^{\circ} \cdot m_{t}-p_{t}=\gamma+\alpha\left(E\left(p_{t+1} \mid I_{t}\right)-p_{t}\right)+v_{t}$

This can be rewritten in the form of equation (18) as:

25. $p_{t}=\frac{-1}{1-\alpha} \gamma+\frac{-1}{1-\alpha} m_{t}-\frac{\alpha}{1-\alpha} E\left(p_{t+1} \mid I_{t}\right)-\frac{1}{1-\alpha} v_{t}$

The noncausal solution of this is:

26a. $p_{t}=\frac{1}{1-\alpha} \sum_{i=0}^{\infty}\left[\frac{-\alpha}{1-\alpha}\right]^{1} E\left(m_{t+1} \mid I_{t}\right)-\left[\frac{1}{1-\alpha}\right]_{i=0}^{\infty} \sum_{i=0}^{\infty}\left[\frac{-\alpha}{1-\alpha}\right]^{i}$

$$
+\lim _{N \rightarrow \infty}\left[\frac{-\alpha}{1-\alpha}\right]^{N} E\left(p_{t+N} \mid I_{t}\right)-\frac{1}{1-\alpha} v_{t}
$$

For this to be stable we require $\left|\frac{-\alpha}{1-\alpha}\right|<1$. Assuming this to be the case, and assuming that the one but last term on the r.h.s. of (26a) vanishes, the noncausal solution is: 
$26 a^{\prime}: \quad p_{t}=-\gamma+\frac{1}{1-\alpha} \sum_{i=0}^{\infty}\left[\frac{-a}{1-\alpha}\right]^{i} E\left(m_{t+i} \mid I_{t}\right)-\left(\frac{1}{1-i l}\right) v_{t}$

The current price level is a function of the current and anticipated future money supplies and the current money market disturbance. Specifically, an equal proportional inerease in period $t$ in the current and anticipated future money supplies raises the price level immediately, i.e., In period $t$, and by the same proportion. Contrast this with a causal solution of (25) given in $(26 b)$.

26b. $p_{t}=-\frac{1}{\alpha} \gamma+\frac{\alpha-1}{a} p_{t-1}+\frac{1}{\alpha} m_{t-1}-\frac{1}{a} v_{t-1} \underline{12 /}$

In contrast to equation $\left(26 a^{\circ}\right)$, an increase in the money supply in period $t$, even when fully anticlpated, will have no effect on the price level in period t. A fully anticipated increase in the money stock affects the price level with a one-period lag. Also, unless $\alpha=1$, the past price level will affect the current price levil. Such inertia is generally viewed as inconsistent with an efficient mirhet. If we take a more general causal solution:

$$
p_{t}=-\frac{1}{\alpha} \gamma+\frac{\alpha-1}{\alpha} p_{t-1}+\frac{1}{\alpha} m_{t-1}-\frac{1}{\alpha} v_{t-1}+\psi_{t} v_{t}+\phi_{t}\left(m_{t}-E\left(m_{t} \mid I_{t-1}\right)\right)
$$

we obtain the further paradox that only unanticipated monetary shocks or nonetary "innovations" will affect the current price level, and with arbitrary sign and magnitude! Both $\left(26 a^{\circ}\right)$, a "New Classical" equation, and (26b), an "Old Keynesian" equation, are consistent with financial equilibrium and rational expectations. The policy implications of the two solutions are vastly different.

The existence of causal representations and solutions of more general rational expectations models incorporating current and past expectations of endogenous variables any number of periods into the future can be established by analogy with equations $\left(18^{\circ}\right)$ and $(20)$. By direct computation it can also 
be shown that linear combinations of the causal and the noncausal solutions with weights summing to unity are also a solution to (18). Additional information from outside the formal model is required to make the chofce between the causal solution, the noncausal solution, and mixtures of the causal and the noncausal solutions. This is true in rational expectations models as in any dynamic model. The noncausal solution appears, on a priort economic grounds, to be the appropriate one for variables such as asset prices determined in efficient markets. In such models current asset prices are a function of expected future asset prices, and current prices can respond instantaneously to changes in information. For prices determined in inefficient markets the causal solution would seem to be the appropriate one. The choice between the causal, noncausal and mixed solutions should be made without reference to stability considerations. If the noncausal solution is chosen, e.g., because of considerations of market efficiency, we may use long-run rationality considerations to restrict the economic system to the unique convergent saddle path, should such a path exist. In general, unless instability were to violate physical or behavioral constraints, it would seem inappropriate to single out the stable solution as the only appropriate one. There is no divine guarantee that the economic system is stable. 
v. Optimal feedback rules in non-causal models: the

If the noncausal. solution is chosen for a dynamic model, traditional optimal control thenry runs into trouble. In this section a simple twoperiod example due to Kydland and Prescott [1977] is analyzed that brings out the issues clearly. It will be shown that the "inconsistency of optimal plans" problem is not due to explicit multi-player game considerations nor to uncertainty, but to the noncausal structure of the model. The reason for the noncausal structure of the model is likely to be the presetice of optimizing agents with rational expectations of the future. A deterininistic model is considered first, followed by a stochastic version of the sane model.

\section{A certainty model}

The dynamic model is given in equation (27), the objective function to be minimized in $(28)$.

27. ... $y_{t}=E\left(y_{t-1}, x_{t}, x_{t+1}\right)$

28. $\min W\left(y_{1}, y_{2}, x_{1}, x_{2}\right)$

29a. $y_{0}=\bar{y}_{0}$

29b. $\quad x_{3}=\bar{x}_{3}$

The model is noncausal because the current state depends on a future instrument value. An initial condition for $y_{0}$ and a terminal condition for $x_{3}$ are needed to make this a well-defined problen.

The optimum policy can be derived by minimizing (27) with respect to $x_{1}$ and $x_{2}$ subject to the constraints (27), (29a) and (29b). This optimum solution is open-loop, i.e., it does not "take advantage" of the time 
structure of the model. Substituting the constraints into the objective function we obtain:

$$
W=W\left(f\left(\bar{y}_{0}, x_{1}, x_{2}\right), f\left(y_{1}, x_{2}, \bar{x}_{3}\right), x_{1}, x_{2}\right)
$$

Assuming differentiability and an interior solution, the first order conditions for a minumum are: $\frac{\partial W}{\partial x_{1}}=0$ and $\frac{\partial W}{\partial x_{2}}=0$. This yields

30a. $\quad \frac{\partial W}{\partial y_{1}} \frac{\partial y_{1}}{\partial x_{1}}+\frac{\partial W}{\partial y_{2}} \frac{\partial y_{2}}{\partial y_{1}} \frac{\partial y_{1}}{\partial x_{1}}+\frac{\partial W}{\partial x_{1}}=0$

30b. $\frac{\partial W}{\partial y_{1}} \frac{\partial y_{1}}{\partial x_{2}}+\frac{\partial W}{\partial y_{2}} \frac{\partial y_{2}}{\partial y_{1}} \frac{\partial y_{1}}{\partial x_{2}}+\frac{\partial W}{\partial y_{2}} \frac{\partial y_{2}}{\partial x_{2}}+\frac{\partial W}{\partial x_{2}}=0$

or

$30 a^{\prime} \cdot\left(w_{1}+w_{2} f_{1}\left(y_{1}, x_{2}, \bar{x}_{3}\right)\right) f_{2}\left(\bar{y}_{0}, x_{1}, x_{2}^{\star}\right)+w_{3}=0$

$30 b^{\prime} \cdot\left(w_{1}+w_{2} f_{1}\left(y_{1}, x, \bar{x}_{3}\right)\right) f_{3}\left(\bar{y}_{0}, x+x_{1}\right)+w_{2} f_{2}\left(y_{1}, x_{2}, \bar{x}_{3}\right)+w_{4}=0$

Clearly, policy optimization is possible in noncausal models: $\left(30 a^{\circ}\right)$ and $\left(30 b^{\prime}\right)$ permit the (implicit) solution of $x \frac{1}{1}$ and $x_{2}^{*}$, the values of $x_{1}$ and $\mathrm{x}_{2}$ that minimize $\mathrm{W}$, assuming the second order conditions for a minimum are satisfied. This optimal solution is in open-loop form, i.e., it is not state-dependent.

The consistent solution, in the sense of Kydland and Prescott, is the solution derived by traditional dynamic programing methods that attinpt to exploit the time structure of the model. Starting from period 2, the value function for the last period $\vec{W}$ is minimized with respect to $x_{2}$, taking as given the values of $y_{1}$ and $x_{1}$. I.e., the dependence of $y_{1}$ on $x_{2}$, modeled in equation (27), is ignored. The "optimum" value of $x_{2}, \hat{x}_{2}$ is then substituted into $\hat{W}$ to yield $\hat{\widehat{W}}$. The optimization problem for period 1 consists in selecting the value of $x_{1}$ that minimizes $W$, given that $x_{2}=\widehat{x}_{2}$. Without entering into a semantic argument, it is clear that the "consistent" policy 
should be perceived as suboptimal. It is therefore unlikely to be adopted by sensible econoric agents. Well-informed agents who know the true structure of the molel will be aware of the dependence of $y_{t-1}$ on $x_{t}$ and will consequently not treat $y_{t-1}$ as predetermined when selecting the optimal feedback rule for $x_{t}$. In a model without uncertainty, the open-1oop policy will be chosen.

Applying dynamic programming, the period 2 problem is: min $\overline{\overline{\mathrm{W}}}$, i.e., $\mathrm{x}_{2}$

$\min W\left(y_{1}, f\left(y_{1}, x_{2}, \bar{x}_{3}\right), x_{1}, x_{2}\right)$, treating $y_{1}$ and $x_{1}$ as given. The first order condition is: $x_{2}$

31a. $\frac{\partial W}{\partial y_{2}} \frac{\partial y_{2}}{\partial x_{2}}+\frac{\partial W}{\partial x_{2}}=0$

or

$31 a^{\circ} \cdot w_{2} f_{2}\left(y_{1}, \bar{x}_{2}, \bar{x}_{3}\right)+w_{4}=0$

This gives a consistent closed-loop solution for $\hat{x}_{2}$

32. $\cdots \bar{x}_{2}=h\left(y_{1}, x_{1}, \bar{x}_{3}\right)$

with

33a. $h_{1}=-\left[f_{2}\left(w_{2,1}+w_{2,2} f_{1}\right)+w_{4,1}+w_{4,2} f_{1}+w_{2} f_{2,1}\right] \cdot 2$

33b. $h_{2}=-\left[\mathrm{E}_{2} \mathrm{~W}_{2,3}+\mathrm{w}_{4,3}\right] \Omega$

33c. $\quad h_{3}=-\left[\mathrm{f}_{2} \mathrm{~W}_{2,2} \mathrm{f}_{3}+\mathrm{W}_{2} \mathrm{f}_{2,3}+\mathrm{W}_{4,2} \mathrm{f}_{3}\right] \cdot \Omega$

33d. $\Omega=\left[\mathrm{f}_{2}\left(\mathrm{~W}_{2,4}+\mathrm{w}_{2,2} \mathrm{f}_{2}\right)+\mathrm{W}_{2} \mathrm{f}_{2,2}+\mathrm{w}_{4,4}+\mathrm{w}_{4,2} \mathrm{f}_{2}\right]^{-1}$

The period 1 optimization problem is:

$\min \bar{W}$ i.e., min $W\left(y_{1}, E\left(y_{1}, \widehat{x}_{2}, \bar{x}_{3}\right), x_{1}, \widehat{x}_{2}\right)$

$\mathrm{x}_{1}$

$\mathrm{x}_{1}$

$=W\left(f\left(y_{0}, x_{1}, \hat{x}_{2}\right), f\left(f\left(y_{0}, x_{1}, \hat{x}_{2}\right), \hat{x}_{2}, \bar{x}_{3}\right), x_{1}, \widehat{x}_{2}\right)$

Noting that $\hat{x}_{2}=h\left(y_{1}, x_{1}, \bar{x}_{3}\right)=h\left(f\left(y_{0}, x_{1}, \hat{x}_{2}\right), x_{1}, \bar{x}_{3}\right)$, we can solve for $\hat{x}_{2}$ as a function of $y_{0}, x_{1}$ and $\bar{x}_{3}$ :

34. $\bar{x}_{2}=g\left(y_{0}, x_{1}, \bar{x}_{3}\right)$ 
35a. $g_{1}=\left[1-h_{1} f_{3}\right]^{-1} h_{1} f_{1}$

35b. $g_{2}=\left[1-h_{1} E_{3}\right]^{-1}\left[h_{1} \varepsilon_{2}+h_{2}\right]$

$35 c \cdot \quad g_{3}=\left[1-h_{1} f_{3}\right]^{-1} h_{3}$

The optimization problem for period 1 can now be written a:

$\min w\left[f\left(y_{0}, x_{1}, g\left(y_{0}, x_{1}, \bar{x}_{3}\right), f\left[f\left(y_{0}, x_{1}, g\left(y_{0}, x_{1}, \bar{x}_{3}\right)\right), g\left(y_{0}, x_{1}, \bar{x}_{3}\right), \bar{x}_{3}\right], x_{1}\right.\right.$,

$\mathrm{x}_{1}$. $\left.g\left(y_{0}, x_{1}, \bar{x}_{3}\right)\right]$.

The first order condition is

31b. $\frac{\partial w}{\partial y_{1}}\left(\frac{\partial y_{1}}{\partial x_{1}}+\frac{\partial y_{1}}{\partial x_{2}} \frac{\partial x_{2}}{\partial x_{1}}\right)+\frac{\partial W}{\partial y_{2}}\left(\frac{\partial y_{2}}{\partial y_{1}}\left(\frac{\partial y_{1}}{\partial x_{1}}+\frac{\partial y_{1}}{\partial x_{2}} \frac{\partial x_{2}}{\partial x_{1}}\right)+\frac{\partial y_{2}}{\partial x_{2}} \frac{\partial x_{2}}{\partial x_{1}}\right)$

$+\frac{\partial W}{\partial x_{1}}+\frac{\partial W}{\partial x_{2}} \frac{\partial x_{2}}{\partial x_{1}}=0$

or:

$31 b^{\prime} \cdot w_{1}\left(f_{2}\left(y_{0}, \widehat{x}_{1}, \widehat{x}_{2}\right)+f_{3}\left(y_{0}, \widehat{x}_{1}, \widehat{x}_{2}\right) g_{2}\left(y_{0}, \widehat{x}_{1}, \bar{x}_{3}\right)\right)$

$+w_{2} l\left(f_{1}\left(y_{1}, \hat{x}_{2}, \bar{x}_{3}\right)\left(f_{2}\left(y_{0}, \widehat{x}_{1}, \hat{x}_{2}\right)+f_{3}\left(y_{0}, \hat{x}_{1}, \hat{x}_{2}\right) g_{2}\left(y_{0}, \hat{x}_{1}, \vec{x}_{3}\right)\right)\right.$

$\left.+\mathrm{f}_{2}\left(\mathrm{y}_{1}, \hat{\mathrm{x}}_{2}, \overline{\mathrm{x}}_{3}\right) \mathrm{g}_{2}\left(\mathrm{y}_{0}, \hat{\mathrm{x}}_{1}, \overline{\mathrm{x}}_{3}\right)\right]+\mathrm{w}_{3}+\mathrm{w}_{4} \mathrm{~g}_{2}\left(\mathrm{y}_{0}, \hat{\mathrm{x}}_{1}, \overline{\mathrm{x}}_{3}\right)=0$

A comparison of $(30 b)$ or $\left(30 b^{\circ}\right)$ and $\left(3 l_{z}\right)$ or $\left(31 a^{\circ}\right)$ shows that in general the optimal plan and the conststent plan will not be the same. Only if the effect of $x_{2}$ on $y_{1}$ is zero (i.e. $\frac{\partial y_{1}}{\partial x_{2}}=0$ ) or if the effect of changes in $y_{1}$ on $w$ both directly and indirectly through $y_{2}$ is zero (i.e., $\frac{\partial W}{\partial y_{1}}+\frac{\partial W}{\partial y_{2}} \frac{\partial y_{2}}{\partial y_{1}}=0$ ) will the consistent policy be optimal and vice versa.

There is, however, a quite plausible condition that ensures $\frac{\partial W}{\partial y_{1}}+\frac{\partial W}{\partial y_{2}} \frac{\partial y_{2}}{\partial y_{1}}=0$

in the optimal program. This is that the controller does not attach any intrinsic utility or disutility to (changes in) his first-period

instrument. From equation (30a),

if $\frac{\partial W}{\partial x_{1}}=0$ then $\frac{\partial W}{\partial y_{1}}+\frac{\partial W}{\partial y_{2}} \frac{\partial y_{2}}{\partial y_{1}}=0$, assuming $\frac{\partial y_{1}}{\partial x_{1}} \neq 0$.

Take, e.g., the simple linear model with the quadratic objective function: 


$$
\begin{array}{ll}
\text { 36a. } y_{t}=a y_{t-1}+\gamma x_{1}+\delta x_{t+1} & a, r, s, \neq 0 \\
\text { 36b. } y_{0}=\bar{y}_{0}=0 \\
\text { 36c. } x_{3}=\bar{x}_{3}=0 \\
\text { 37. } w=k_{1}\left(y_{1}-a_{1}\right)^{\prime 2}+k_{2}\left(y_{2}-a_{2}\right)^{2} \quad k_{1}, k_{2}>0 .
\end{array}
$$

The optimal policy for this model is:

$$
\begin{aligned}
& x_{1} *=\left[(\alpha \delta+\gamma) a_{1}-\delta a_{2}\right] \gamma^{-2} \\
& x_{2}^{*}=\left[a_{2}-a_{i 1}\right] \gamma^{-1}
\end{aligned}
$$

The consistent policy is

$$
\begin{aligned}
& \hat{x}_{1}=\left[(\alpha \delta+\gamma) a_{1}-\delta a_{2}\right] \gamma^{-2} \\
& \hat{x}_{2}=\left[a_{2}-\alpha y_{1}\right] \gamma^{-1}=\left[a_{2}-\alpha a_{1}\right] \gamma^{-1}
\end{aligned}
$$

The consistent and optimal policies are the same, as expected, because $\frac{\partial W}{\partial x_{1}}=0$. It is a worthwhile topic for future research to investigate whether the 2-period result that instrument costs are necessary for optimal plans to be inconsistent can be generalized in some way to the general nperiod case.

I next modify the objective function of (37) to generate inconsistency of the optimal plan
38.
$w=k_{1}\left(y_{1}-a_{1}\right)^{2}+k_{2}\left(y_{2}-a_{2}\right)^{2}+k_{3}\left(x_{1}-a_{3}\right)^{2}$
$k_{1}, k_{2}, k_{3}>0$

The optimal policy is:

39a. $x_{1} \star=\frac{\gamma^{2}\left[a_{1}(\alpha \delta+\gamma)-a_{2} \delta\right] k_{1} k_{2}+a_{3} \delta^{2} k_{1} k_{3}+a_{3}(\alpha \delta+\gamma)^{2} k_{2} k_{3}}{\gamma^{4} k_{1} k_{2}+\delta^{2} k_{1} k_{3}+(\alpha \delta+\gamma)^{2} k_{2} k_{3}}$

39b. $\quad x_{2} *=\frac{\gamma^{3}\left[a_{2}-\alpha a_{1}\right] k_{1} k_{2}+\delta\left[a_{1}-\alpha a_{3}\right] k_{1} k_{3}+(\alpha \delta+\gamma)\left[a_{2}-\alpha \gamma a_{3}\right] k_{2} k_{3}}{\gamma^{4} k_{1} k_{2}+\delta^{2} k_{1} k_{3}+(\alpha \delta+\gamma)^{2} k_{2} k_{3}}$

The consistent policy for perlod 2 is derived by choosing $x_{2}$ to minimize $k_{2}\left(y_{2}-a_{2}\right)^{2}$, treating $y_{1}$ as predetermined. This yields: 
40a. $\widehat{x}_{2}=\left[a_{2}-a y_{1}\right]^{-1}$

Note that this implies $y_{2}=a_{2}$.

The consistent policy for period 1 is derived by choosing $x_{1}$ to minimize $k_{1}\left(y_{1}-a_{1}\right)^{2}+k_{3}\left(x_{1}-a_{3}\right)^{2}$, given that $x_{2}$ is given by (40a). This yields:

40 b. $. \quad \hat{x}_{1}=\frac{\left((i \delta+\gamma) a_{1}-\delta a_{2}\right) \gamma^{2} k_{1}+(x \delta+\gamma)^{2} a_{3} k_{3}}{k_{1} \gamma^{4}+k_{3}(\alpha \delta+\gamma)^{2}}$

Using $\hat{x}_{2}=\left[a_{2}-\alpha \gamma \hat{x}_{1}\right][1 \delta \delta+\gamma]^{-1}$, equation $(40 a)$ can be rewritten as:

$4 \mathrm{O}^{\prime} \cdot \hat{\mathrm{x}}_{2}=\frac{\left(\mathrm{a}_{2}-\alpha \mathrm{a}_{1}\right) \gamma^{3} \mathrm{k}_{1}+\left(\mathrm{a}_{2}-\alpha \gamma \mathrm{a}_{3}\right)(\alpha \delta+\gamma) \mathrm{k}_{3}}{k_{1} \gamma^{4}+\mathrm{k}_{3}(\alpha \delta+\gamma)^{2}}$

Comparing (39a) with $(40 b)$ and (39b) with $\left(400^{\circ}\right)$ we note that in a model without uncertainty the "consistent" policy is suboptimal and the optimal policy is inconsistent. This conclusion needs to be qualified in a major way when uncertainty is introduced.

\section{A stochastic model}

The stochastic version of the optimization problem given in equations $(36 \mathrm{a}, \mathrm{b}, \mathrm{c})$ and $(37)$ is given below:

$\operatorname{minimize} w=\operatorname{ain} E_{1}\left[k_{1}\left(y_{1}-a_{1}\right)^{2}+k_{2}\left(y_{2}-a_{2}\right)^{2}+k_{3}\left(x_{1}-a_{3}\right)^{2}\right]$

subject to:

41 .

$$
\begin{aligned}
& y_{t}=\alpha y_{t-1}+\gamma x_{t}+\delta E\left(x_{t+1} \mid I_{t}\right)+u_{t} \\
& y_{0}=\bar{y}_{0}=0 \\
& x_{3}=\bar{x}_{3}=0
\end{aligned}
$$

$E_{t}$ denotes the expectiation operator conditional on the information available at the beginning of perfod $t$, before $y_{t}$ or $u_{t}$ have been observed. When open-loop solutions are considered, $E\left(x_{t+1} \mid I_{t}\right)=x_{t+1}$. The optimal openloop policy under uncertainty is the same as the optimal (open-loop) policy under certainty, given in (39a) and (39.b). However, an open-loop policy 
cannot be truly optimal in a stochastic model. If a $\neq 0, y_{t}$ is a function of $y_{t-1}$ (in our model $y_{2}$ is a function of $y_{1}$ ). When the optimal open-loop policy for periods 1 and 2 is chosen at the beginning of period $1, y_{1}$ is unknown because it depends on the realization of the as yet unobserved disturbance $u_{1}$. After $t=1, u_{1}$ will be known. Any truly optimal policy rule for $x_{2}$ would enable it to respond to $u_{1}$. Conventional feedback policies that make $x_{t}$ a function of $y_{t-1}$ enable the policy instruments to respond to new information as it accrues. This advantage of feedback control in the presence of random disturbances has to be balanced against the disadvantage, highlighted in the certainty model: feedback control that makes $x_{t}$ a function of $y_{t-1}$ does not allow fully for the effect of future instrument values on the current state, both directly and indirectly through the effect of future instrument values on the optimal choice of current instrument values. Whether optimal open-loop control dominates or is dominated by feedback control can now only be determined on a case-by-case basis. Note, however, that a more sophisticated kind of feedback control will not be subject to the Kydland-Prescott criticism. Optimal feedback control would make $x_{t}$ a function of $u_{t-1}$, the random disturbance in the previous period. $y_{t-1}$ is a function of $x_{t}$. To treat it as predetermined In the derivation of the "consistent" solution for $x_{t}$ is suboptimal in almost all cases. $u_{t-1}$ is not a function of $x_{t}$ but does convey useful information for the optimal choice of $x_{t}$. A truly optimal polfcy incorporates the dependence of $y_{t-1}$ on $x_{t}$ and allows a flexible response of future instrument values to future random disturbances. It will therefore be "innovation" or "disturbance"contingent rather than state-contingent as in traditional feedback control. In a model with certainty the "innovation 
response" component of the optimal policy rule vanishes and the optimal rule is open-loop. Traditional state-contingent feedback policies may or may not be superior to the optimal open-loop policy, depending on the parameters of the model under consideration. There always exists an Innovation-contingent feedback rule that is superior to the optimal openloop policy. These points are fllustrated with some simple examples. The consistent or "state-dependent" feedback policy

The consistent policy for period 2 is derived by choosing $x_{2}$ to minimize $E\left(k_{2}\left(y_{2}-a_{2}\right){ }^{2}\left(I_{2}\right), 13 /\right.$ treating $y_{1}$ as given. $y_{2}=\alpha y_{1}+\gamma x_{2}+u_{2}$. The solution for $x_{2}$ is:

$$
\text { 42a. } \quad \bar{x}_{2}=\left[a_{2}-\alpha y_{1}\right] \gamma^{-1}
$$

Note that this choice of $x_{2}$ implies that $E\left(y_{2}-a_{2} \mid I_{2}\right)=0$. The consistent solution for $x_{1}$ is found by choosing $x_{1}$ to minimize $E\left(k_{1}\left(y_{1}-a_{1}\right)^{2}+k_{2}\left(y_{2}-a_{2}\right)^{2}\right.$ $+k_{3}\left(x_{1}-a_{3}\right)^{2}\left(I_{1}\right)$ given that $x_{2}$ is set according to (42a). This implies that $E\left(y_{2}-a_{2} \mid I_{1}\right)=0$.

The solution for $x_{1}$ is:

42b. $\widehat{x}_{1}=\frac{\left((\alpha \delta+\gamma) a_{1}-\delta a_{2}\right) \gamma^{2} k_{1}+(\alpha \delta+\gamma)^{2} a_{3} k_{3}}{k_{1} \gamma^{4}+k_{3}(\alpha \delta+\gamma)^{2}}$

Comparing $(42 a)$ and $(42 b)$ with $(40 a)$ and $(40 b)$ we note that the consistent solution is the same with and without uncertainty, provided the solution is expressed in feedback form. Under certainty, however, the consistent solution is suboptimal and the optimal open-loop solution is the truly optimal solution. With uncertainty the expected loss under the optimal open-loop policy may either be smaller or larger than the expected loss under the consistent policy. This is because the optimal open-loop policy is not truly optimal because it cannot respond to future random disturbances. The 
optimal open-loop policy may be dominated not only by the consistent policy but also by simple ad-hoc (linear) feedback rules that permit future instrument values to respond to new information. The rankine of the various policies depends on all the parameters of the model under consideration and can only be established on a case-by-case basis.

To compare the expected loss under the optimal open-loop policy and the consistent policy we must evaluate

$$
E\left[k_{1}\left(y_{1}-a_{1}\right)^{2}+k_{2}\left(y_{2}-a_{2}\right)^{2}+k_{3}\left(x_{1}-a_{3}\right)^{2} \mid I_{1}\right] \text { under the two regimes. }
$$

Thus, for the open-loop policy we evaluate

43a. $h^{*}=E\left[k_{1}\left(\gamma x_{1}{ }^{*}+\delta x_{2}{ }^{*}+u_{1}-a_{1}\right)^{2}+k_{2}\left(\alpha \gamma x_{1}{ }^{*}+(\alpha s+\gamma) x_{2} *+v u_{1}+u_{2}-a_{2}\right)^{2}\right.$

$$
\left.+k_{3}\left(x_{1} *-a_{3}\right) 2 / I_{1}\right]
$$

while for the consistent policy we evaluate

$$
\text { 43b. } \begin{aligned}
\hat{W}= & E\left[k_{1}\left(y \widehat{x}_{1}+\delta E\left(\hat{x}_{2} \mid I_{1}\right)+u_{1}-a_{1}\right)^{2}+k_{2}\left(\alpha \gamma \hat{x}_{1}+\alpha \delta E\left(\hat{x}_{2} \mid I_{1}\right)\right.\right. \\
& \left.\left.+\alpha u_{1}+\gamma \hat{x}_{2}+u_{2}-a_{2}\right)^{2}+k_{3}\left(\hat{x}_{1}-a_{3}\right)^{2} \mid I_{1}\right] .
\end{aligned}
$$

Note that

$44 a \cdot E\left(\hat{x}_{2} \mid I_{1}\right)=\left[a_{2}-\alpha \gamma \widehat{x}_{1}\right](\alpha \delta+\gamma)^{-1}$

44b. $\hat{\mathbf{x}}_{2}=a_{2} \gamma^{-1}-\alpha \hat{x}_{1}-\alpha \gamma^{-1} \delta E\left(\hat{x}_{2} \mid I_{1}\right)-\alpha \gamma^{-1} u_{1}$

$$
=\left[a_{2}-\alpha \gamma \widehat{x}_{1}\right](\alpha \delta+\gamma)^{-1}-\alpha \gamma-1 u_{1} \text {. }
$$

To simplify the calculations, it is assumed that $a_{1}=a_{2}=0$. As regards the random disturbances it is assumed that $E\left(u_{1}\right)=E\left(u_{2}\right)=E\left(u_{1} u_{2}\right)=0$ and $E\left(u_{1}{ }^{2}\right)=E\left(u_{2}{ }^{2}\right)=\sigma_{u}^{2}$. Substituting (39a) and (39b) into $(43 a)$ and (43b), (44a) and ( $44 b)$ into $(43 b)$ we obtain: 
$-55-$

$$
\begin{aligned}
& W^{*}=E_{0}\left(k_{1}\left(\frac{a_{3} \gamma^{2}(\alpha s+\gamma) k_{2} k_{3}}{\gamma^{k_{k_{1}} k_{2}}+\delta^{2} k_{1} k_{3}+(a s+\gamma)^{2} k_{2} k_{3}}+u_{1}\right)^{2}\right. \\
& +k_{2}\left(\frac{-a_{3} \delta \gamma^{2} k_{1} k_{3}}{\gamma^{4} k_{1} k_{2}+\delta k_{1} k_{3}+(a \delta+\gamma)^{2} k_{2} k_{3}}+a u_{1}+u_{2}\right)^{2} \\
& +k_{3}\left(\frac{-a_{3} \gamma^{4} k_{1} k_{2}}{\gamma^{4} k_{1} k_{2}+\delta^{2} k_{1} k_{3}+(\alpha \delta+\gamma)^{2} k_{2} k_{3}}\right)^{2}\left[I_{1}\right] \\
& \hat{W}=E\left[k_{1} \frac{a_{3} \gamma^{2}(\alpha \delta+\gamma) k_{2} k_{3}}{\gamma^{4} k_{1} k_{2}+(\alpha \delta+\gamma)^{2} k_{2} k_{3}}+u_{1}\right)^{2} \\
& \left.+k_{2}\left(u_{2}\right)^{2}+k_{3}\left(\frac{-a_{3} \gamma^{4} k_{1} k_{2}}{\gamma^{4} k_{1} k_{2}+(\alpha \delta+\gamma)^{2} k_{2} k_{3}}\right)^{2} \mid I_{1}\right]
\end{aligned}
$$

Therefore,

45.

$$
\begin{aligned}
w^{*}-\hat{W}= & k_{1}\left[\left(\frac{a_{3} \gamma^{2}(\alpha \delta+\gamma) k_{2} k_{3}}{\gamma^{4} k_{1} k_{2}+\delta^{2} k_{1} k_{3}+(\alpha \delta+\gamma)^{2} k_{2} k_{3}}\right)^{2}-\left(\frac{a_{3} \gamma^{2}(\alpha \delta+\gamma) k_{2} k_{3}}{\gamma^{4} k_{1} k_{2}+(\alpha \delta+\gamma)^{2} k_{2} k_{3}}\right)^{2}\right] \\
& \left.+k_{2} \frac{a_{3} \delta \gamma^{2} k_{1} k_{3}}{\gamma^{4} k_{1} k_{2}+\delta^{2} k_{1} k_{3}+(\alpha \delta+\gamma)^{2} k_{2} k_{3}}\right)^{2}+k_{2} \alpha^{2} \sigma_{u}^{2} \\
& +k_{3}\left[\left(\frac{a_{3} \gamma^{4} k_{1} k_{2}}{\gamma^{4} k_{1} k_{2}+\delta k_{1} k_{3}+(\alpha \delta+\gamma)^{2} k_{2} k_{3}}\right)^{2}-\left(\frac{a_{3} \gamma^{4} k_{1} k_{2}}{\gamma^{4} k_{1} k_{2}+(\alpha \delta+\gamma)^{2} k_{2} k_{3}}\right)^{2}\right]
\end{aligned}
$$

Except for the term $k_{2} \alpha^{2} \sigma_{u}{ }^{2}$, equation (45) also measures the diffference between the loss under the optimal (open-loop) policy and the loss under the consistent policy in the case without uncertainty. Therefore, 46. $\quad W *-\hat{W}-k_{2} \alpha^{2} \sigma_{u}^{2}<014$ I 
With uncertainty however, it is quite possible that the minimum expected loss under the consistent policy is less than that under the optimal openloop policy. A sufficiently large value of $\sigma_{u}{ }^{2}$ will ensure this, if $k_{2}$ and $\alpha$ are not equal to zero. It can also be shown that there exist adhoc state-contingert feedback policies of the form $x_{t}=B_{t}+G_{t} y_{t-1}$ that have a minimum expected loss less than the optimal open-loop policy. There may also exist more general, non-linear feedback policies that have this property, but I have made no attempt to establish this.

An Innovation-dependent feedback policy

It is easily established that the optimal open-loop policy given by $x_{1} *$ and $x_{2}$ * in (39a) and (39b) is dominated by an innovation-contingent feedback policy that has the optimal open-loop policy $\left(x_{1} *, x_{2} *\right)$ as its open-loop component. Consider a linear feedback policy of the following kind:

46a. $\quad x_{1}=x_{1}$ *

46b. $x_{2}=x_{2}{ }^{*}+G_{1}$

$G$ is to be chosen so as as to minimize $W$

$$
\begin{aligned}
W= & E\left(k_{1}\left(\gamma x_{1}+\delta E\left(x_{2} \mid I_{1}\right)+u_{1}-a_{1}\right)^{2}+k_{2}\left(\alpha \gamma x_{1}+\alpha \delta E\left(x_{2} \mid I_{1}\right)+\gamma x_{2}\right.\right. \\
& \left.\left.+\alpha u_{1}+u_{2}-a_{2}\right)^{2}+k_{3}\left(x_{1}-a_{3}\right)^{2} \mid I_{1}\right)
\end{aligned}
$$

Note that $E\left(x_{2} \mid I_{1}\right)=x_{2}$ *

Substituting $x_{1}, x_{2}$ and $E\left(x_{2} \mid I_{1}\right)$ into the loss function yields

47. $W=E\left(k_{1}\left(\gamma x_{1}{ }^{*}+\delta x_{2}{ }^{*}+u_{1}-a_{1}\right)^{2}+k_{2}\left(\alpha \gamma x_{1} *+(\alpha \delta+\gamma) x_{2}\right.\right.$ *

$$
\left.+\gamma G u_{1}+a u_{1}+u_{2}-a_{2}\right)^{2}+k_{3}\left(x_{1} *-a_{3}\right)^{2}\left(I_{1}\right)
$$


The optimal value of $G$ is the one that exactly neutralizes the effect of $u_{1}$ on $y_{2}$, i.e., $G=-\alpha \gamma^{-1}$

The policy

48a. $x_{1} * *=x_{1}^{*}$

$48 \mathrm{~b}, \quad \mathrm{x}_{2} * *=\mathrm{x}_{2} *-a \gamma^{-1} \mathrm{u}_{1}$

dominates the optimal open-loop policy $x_{1}{ }^{*}, x_{2}{ }^{*}$, as can be seen by comparing $W^{*}$ in $(43 a)$ with $W^{* *}$ below:

49. $W * \star=E\left[k_{1}\left(\gamma x_{1} *+\delta x_{2} *+u_{1}-a_{1}\right)^{2}+k_{2}\left(\alpha \gamma x_{1} *+(\alpha \delta+\gamma) x_{2} *+u_{2}-a_{2}\right)^{2}\right.$

$$
\left.+i_{3}\left(x_{1}^{*}-a_{3}\right)^{2} \mid I_{1}\right]
$$

50. $W^{*}-W^{*} * k_{2} \alpha^{2} \sigma_{u}^{2}>0$

The $\left(x_{1}{ }^{* *}, x_{2}{ }^{* *}\right)$ policy is not "consistent", in the sense of Kydland and Prescott because it cannot be derived by the backward recursive

optimization techniques of stochastic dynamic programming. $\frac{15 /}{}$ The important point to note is that $\left(x_{1}{ }^{*}, x_{2}{ }^{*}\right)$ is a feedback rule or contingent rule and that it dominates the optimal open-loop rule except in the special case of no uncertainty, when the two policies coincide. It is easily checked that the innovation-contingent rule also dominates the consistent policy; from (50), $\mathrm{W}^{* *}=\mathrm{W}^{*}-\mathrm{k}_{2} \alpha^{2} \sigma_{\mathrm{u}}^{2}<\hat{\mathrm{W}}$. For economic policy, the important 
conclusion is that (innovation-contingent) feedback policy dominates openloop policy even in models. with rational expectations of the future.

\section{Conclusion}

There has been a "rational expectations revolution" in macroecononics. The subject will never be the same again. The "princlple of policydependent structural parameters" brings out the need to model stimultaneously the expectation formation process and the stochastic processes governing the behavior of the varlables whose values are being predicted or inferred--stochastic processes that may themselves be functions of the expectation formation process. There is an urgent need to relax the extreme informational requirements of most current macroeconomic rational expectations models and to reformulate the rational expectations hypothesis in terms of a more general optimal Bayesian prediction and inference theory. Such developments are within reach and will in no way diminish the importance of the contribution of Lucas.

The rational expectations revolution has also forced a fundamental rethinking of the dynamic programing approach to optimization in dynamic economic models. In causal models, differential game theory provides the appropriate analytical tool for modeling the interdependence of rational private sector and public sector agents. In noncausal models, Kydland and Prescott's demonstration of the suboptimality of "consistent" plans derived from traditional dynamic programing approaches alters, but does not eliminate the scope for beneficial feedback policy. In models with uncertainty, the optimal open-loop policy need not dominate the "consistent" policy or other, ad-hoc feedback policies that make the values of . 
the current policy instruments some known (linear) function of the information set at the time that the policy instrument value must be set. The optimal open-100p policy is dominated by the optimal linear innovation-contingent feedback rule that sets the current values of the policy instruments equal to their optimal open-loop values plus a linear function of the past random disturbance vector. There is no presumption that a suboptimal, restricted open-loop policy such as a constant growth rate for the stock of money will generate desirable outcomes in nacroeconomic models that incorporate a variety of internal and external disturbances. Acceptance of the importance of the contribution of the rational expectations hypothesis should, however, be kept quite separate from one's view on the value of the remainder of the New Classical Macroeconomics package. That remainder--the general application of the efficient market hypothesis to goods and factor markets, the monetary neutrality and superneutrality postulates, the debt neutrality theorem and the other assumptions underlying what I have called the "public sector-private sector Liodigliani-Miller theorem". (Buiter $[1975,1979])--d o e s$ not constitute a promising approach to the analysis and control of real-world economic systems. The theoretical case against debt neutrality and against monetary neutrality and superneutrality is overwhelming (e.g., Buiter [1979] and Fischer [1979]). The microeconomic foundations of inefficient markets are in the process of being developed. Noncooperative game theory, bargaining theory and the theory of production and exchange under asymmetric, imperfect and costly information are the starting point for the New Keynesian Macroeconomics. 


\section{Footnotes}

*This paper was written while I was a consultant with the Financial Studies

Division of the Research Department of the International Monetary Fund. The opinions expressed are my own. I would like to thank Mohsin Khan and

Don Mathieson for discussions on causal and noncausal solutions to dynamic models, and George von Furstenberg for comments on an earlier draft.

I/ An excellent early survey of the role of monetary and real factors in the trade cycle is Haberler [1956]. While emphasizing the importance of the money supply process and of financial factors in general, he also considers price and wage rigidity to be necessary elements in the transmission mechanism. His emphasis on "large fixed monetary contracts" (p. 139, p. 140) is also surprisingly "modern".

2/ Price stickiness is consistent with only unanticipated policy having an efFect on real output or employment as long as production and employment depend only on price surprises and not on the actual price. McCallum [1977, 1978] has sticky prices but equates the quantity produced to the notional supply of output which is a function of the price surprise only. One can have a "disequilibrium" determination of production by assuming that actual output is the "min." of the effective demand for and the efffective suppiy of output. As long as both effective demand and effective supply are functions of price surprises only, policy ineffectiveness follows.

3/ An early characterization of a "rational expectations equilibrium can be found in Hayek [1935]. "The main difficulty of the traditional approach is its complete abstraction from time. A concept of equilibrium which essentially was applicable only to an economic system conceived as timeless could not be of great value..... It has become clear that, instead of completely disregarding the time element, we must make very definite assumptions about the attitude of persons towards the future. The assumftions of this kind which are implied in the concept of equil1brium are essentially that everybody foresees the future correctly and that this foresight includes not only the changes in the objective data but also the behavior of all the other people with whom he expects to perform economic transactions" (Italics added).

4/ This is the property that predictions of future variables differ from the actual future outcomes only by errors which are independent of the variables used to generate the predictions. Friedman [1979], p. 24 .

$5 /$ Cruclal in the sense that major qualitative properties of the model depend on it. 
6/ It is assumed that $\mathrm{C}_{i t}{ }^{\circ} \mathrm{H}_{1 t} \mathrm{C}_{1 \mathrm{t}}$ has an inverse for all $i$ and $t$.

If Assuming $\mathrm{K}_{1 \mathrm{~T}+1}=0$ and $\mathrm{a}_{1 \mathrm{~T}+1}=0$ for all $i$.

8/ Throughout, identical information is assumed to be available to all agents.

9/ Following Calvo [1979a, b] the following proposition holds for wodels in which the $n$-dimensional state vector, $y_{t}$, containes $0 \leq m \leq n$ causal elements, i.e., variables for which an initial value needs to be specified, and $n-m \geq 0$ noncausal elements, $i . e$. , Jariables that cannot be treated as predetermined and for which a terminal value needs to be specified. There exists a unique equilibrium saddle-path of the system $y_{t}=A y_{t-1}$ that converges to the long-run equiliorium iff $n$ of tine characteristic roots of $A$ have modulus less than unity and the remaining $n-m$ characteristic roots have modulus greater than unity. (The original exanpies by Calvo were in terms of differential equation systems, but the substance of the argument is the same for difference equation systems.)

10/ It is assumed that $E\left(x_{\tau} \mid I_{\tau}\right)=x_{\tau}$ for all $\tau$.

$11 /$ The solution when $B$ is not invertible is given in Aoki and Canzoneri $[1 \overline{979}]$.

12/ This is the solution corresponding to the one given in (20h) i.e., $\psi_{t}$ and $\phi_{t}\left(\right.$ see Equation $\left(20 h^{\prime \prime}\right)$ ) are set equal to zero.

13! Note that it is assumed that $y_{t}$ and $u_{t}$ are not elements of $I_{t} \cdot x_{t}$ has to be chosen before $y_{t}$ and $u_{t}$ are observed. This assumption can easily be relaxed to include partial or complete contemporaneous observation of $y_{t}$ and $u_{t}$. $14 /$ This can also be checked by reducing all terms in (45) except $\mathrm{k}_{2} \alpha^{2} \sigma_{\mathrm{u}}{ }^{2}$
to common denominator.

15/ In a private communication, Mr. C.R. Birchenhall of Manchester University has shown that the linear innovation contingent policy not only dominates the open-loop policy but also is the global optimal policy for this linear-quadratic model. 
Akerlof, G. (1970) "The Market for 'Lemons' :Qualitative Uncertainty and the Market Mechanism," Quarterly Journal of Economics, 84, August, pp. 488-50o.

Aoki, Masanao, and Matthew Canzoneri. (1979) "Reduced Forms of Rational Expectations Models," Quarterly Journal of Economics, 93, February, pp. 59-71.

Bacharach, Michael, (1976) Economics and the Theory of Games Macmillan, London.

Bacon, Walter, and Eltis, Robert (1978) Britain's Economic Problem : Too Few Producers.

2nd. ed. Macmillan.

Barro, Robert J. (1974) "Are Government Bonds Net Wealth?" Journal of Political Economy 82 , November-December, pp. 1095-117

(1976) "Rational Expectations and the Role of Monetary Policy," Journal of Monetary Economics, 2, January, pp. 1095-1117.

(1977) "Unanticipated Money Growth and Unemployment in the United States," American Economic Review, March, pp. 101-115.

(1978) "Unanticipated Money, Output and the Price Level in the United States," Journal of Political Economy, August, pp. 549-580.

(1979) "Second Thoughts on Keynesian Economics," American Economic Review, Papers and Proceedings, 69, May, pp. 54-9.

Basu, Anupan. (1979) "An Optimal Control Approach to the Determination of Economic Policy." International Monetary Fund, Research Department Memorandum, September 17.

Baumo1, William J., (1952) "The Transactions Demand for Cash: An Inventory Theoretic Approach," Quarterly Journal of Economics, November, pp.545-56.

Blanchard, Olivier, (1979) "Backward and Forward Solutions for Economies with Rational Expectations," American Economic Review, 69, Papers and Proceedings,
May, pp. 114-118.

Brown, Bryan W. and Shlomo Maital, (1979) "What Do Economists Know? An Empirical Study of Experts' Expectations," Woodrow Wilson School Working Paper, Princeton University.

Bryant, John and Wallace Neil, (1979) "The Inefficiency of Interest-bearing National Debt, Journal of Political Economy, 87, April, pp. 365-381.

Buiter, Willem H., (1975) Temporary and Long-run Equilibrium, Yale Ph.D. Thesis, published by Garland Publisning Inc., New York, 1979.

(1979) "The Roles of Monetary, Financial and Fiscal Policy under Rational Expectations," NBER Working Paper No. 412, November.

(1980) "Government Finance in an Overlapping Generations Model with Gifts and Bequests" in George M.von Furstenberg ed. Social Security vs. Private Saving, Ballinger 1980

(1980) "The Macroeconomics of Dr. Pangloss; A Critical Survey of the Nive Classical Macroeconomics," Economic Journal, 90, March, pp. 34-50. 
Buiter Willem H. and James Tobin, (1980) "Debt Neutrality: A Brief Review of Doctrine and Evidence" in George M. von Furstenberg, ed. Social Security vs. Private Saving, Ballinger 1980.

Calvo, Guillermo, 1979a, "Fiscal Policy, Welfare and Employment with Perfect Foresight," Journal of Macroeconomics, 1, Spring 1979.

1979b, "On Models of Money and Perfect Foresight" International Economic Review, 20, February 1979, pp. 83-103.

De Canio, Stephen, (1979) "Rational Expectations and Learning from Experience" Quarterly Journal of Economics, February, pp. 45-57.

Carmichael Jeffrey, (1979) The Role of Government Financial Policy in Economic Growth, Unpublished Ph.D Thesis, Princeton University.

Chow, Gregory, (1975) Analysis and Control of Dynamic Economic Systems, John Wiley and sons, New York.

De Bruyne, Guido, (1975) "Pareto Optimality of Non-Cooperative Equilibrium in a TimeDependent Multi-Period Game." European Economic Review, 12, July, pp. 243-260.

Douglas, Paul, (1932) "Money, Credit and the Depression." The World Tomorrow, 15 March, Pp. 78-80.

(1935) Controlling Depressions, New York: W.W. Norton and Co.

Drazen, Allan, (1980) "Recent Developments in Macroeconomic Disequilibrium Theory," Econometrica, 48, March,pp. 283-306.

Fischer,Stanley, (1977) "Long-term Contracts, Rational Expections and the Optimal Money Supply Role," Journal of Political Economy, February. pp. 191-205.

Fisher, I.-(1933) "Debt Deflation Theory of Great Depressions," Econometrica, 1, October, pp. 337-357.

Friedman B. (1979) "Optimal Expectations and the Extreme Information Assumptions of 'Rational Expectations' Macromodels. Journal of Monetary Economics, 5, January, pp. 23-41.

Friedman, Milton, (1968) "The Role of Monetary Policy," American Economic Review, 58, March, pp. 1-17.

- Grossman, Sanford, (1976) "On the Efficiency of Competitive Stock Markets Where Traders Have Diverse Information," Quarterly Journal of Finance, 31, May, pp.573-85.

Grossman,S. and J. Stiglitz. (1976) "Information and Competitive Price Systems," American Economic Review, May, pp. 246-253.

Haterler, G. (1972) "Money and the Business Cycle" in Gold and Monetary Stabilization, Q. Wright ed. pp. 43-74. Chicago, University of Chicago Press.

(1950) "Yonetary and Real Factors Affecting Economic Stability: A Critique of Certain Tendencies in Modern Economic Theory." in Banca Nazionale Del Lavoro. Quarterly Review, Vol IX, September. Reprinted in Readings in Business Cycles, R.A. Gordon and L.R. Klein eds. Richard D. Irwin Inc. Homewood Illinois, 1965,pp.130-149. 
Hahn, Frank H. (1977), "Exercises in Conjectural Equilibria," Scandinavian Journal of Economics, 79, pp. 210-226.

Hall, Robert E. (1970) "Why is the Unemployment Rate so High at Full Employment?" Brookings Papers on Economic Activity, 3, pp. 369-402.

(1979) "A Theory of the Natural Unemployment Rate and the Duration of Employment," Journal of Monetary Economics, 4, April. pp. 153-170.

Hawtrey, Ralf G. (1926) "The Trade Cycle," De Economist, 1926, reprinted in Readings in Business Cycles, G. Haberler, ed. The Blakiston Co. 1944, Philadelphia pp. 330-349.

Hayek, Friedrich A. (1933) Monetary Theory and the Trade Cycle; Harcourt, Brace and Co. New York.

(1939)"Price Expectations, Monetary Disturbances and Malinvestments." First published in Nationalokonomisk Tidsskrift, vol 73, no, 3, 1935. Reprinted in Readings in Business Cycles G. Haberser, ed. The Blakiston Co. 1944, Philadelphia, pp.350-365.

Intriligator, Michael D. (1971) Mathematical Optimization and Economic Theory, Prentice Ha11, Inc. Englewood Cliffs, N.J.

Knight, Frank, (1941) "The Business Cycle, Interest and Money; A Methodological Approach," Review of Economic Statistics, 23, May, pp. 53-67.

Kyland, F.E. (1975) "Noncooperative and Dominant Player Solutions in Discrete Dynamic Games," International Economic Review, 16, June, pp, 321-335.

and Prescott, E.C. (1977) "Rules Rather than Discretion: The Inconsistency of Optimal Plans" Journal of Political Economy, 85, June, pp. 473-491.

.Lucas, Robert E. (1972a) "Expectations and the Neutrality of Money," Journal of Economic Theory, 4, April, pp, 103-124.

(1972b) "Econometric Testing of the Natural Rate Hypothesis," in 0 . Eckstein ed. The Econometrics of Price Determination, a conference Sponsored by the Board of Governers of the Federal Reserve System and the Social Science Research Council.

(1975) "An Equilibrium Model of the Business Cycle," Journal of Political Economy, 83, December, pp. 1113-44.

(1976) "Econometric Policy Evaluation: A Critique," in The Phillips Curve and Labor Markets, Karl Brunner and Allen H. Meltzer, eds. Ams terdam, North Holland.

and Sargent, T.J. (1978) "After Keynesian Macroeconomics," in After the Phillips Curve: Persistence of High Inflation and High Unemployment, Federal Reserve Bank of Boston, Boston, pp.49-72.

McCallum, Bennett T. (1977)"Price Level Stickiness and the Feasibility of Monetary Stabilization Policy with Rational Expectations." Journal of Political Economy, 85, June, pp, 627-634.

(1978)"Price Level Adjustments and the Rational Expectations Approach to Macroeconomic Stabilization Policy," Journal of Money, Credit and Banking, 10, November, pp.418-436. 
Miller, Merton and Daniel Orr, (1966) "A Model of the Demand for Money by Firms," Quarterly Journal of Economics, August, pp. 413-435.

Muth, J. (1961) "Rational Expectations and the Theory of Price Movements, "Econometrica, 29, July, pp. 315-335.

Negishi, T. (1960) "Monopolistic Competition and General Equilibrium," Review of Economic Studies, 28, pp. 196-201.

Phelps, Edward S. et. al. (1970) Microeconomic Foundations of Employment and Inflation Theory, W.W. Norton, New York.

and John B. Taylor, (1977) "Stabilizing Powers of Monetary Policy under. Rational Expectations," Journal of i'olitica1 Economy, 85, February, pp. 163-190.

Prescott, Edward, (1975) "Efficiency of the Natural Rate," Journal of Political Economy, 83. December, pp. 1229-36.

(1977) "Should Control Theory be used for Economic Stabilization?" in Optimal Policies, Control Theory and Technology Exports, eds. K. Brunner and A.H. Meltzer, Carnegie-Rochester Conference Series on Public Policy, Vol. 7 .

Riley, J. (1977) "Noncooperative Equilibrium and Market Signalling" American Economic Review, 69, Papers and Proceedings, May, pp.303-307.

Salop, S. (1978) "Parables of Information Transmission," in A. Mitchell, ed. The Effect of Information on Consumer and Market Behavior. Chicago.

(1979) "A Model of the Natural Rate of Unemployment." American Economic Review, 69, March, pp. 117-125.

Sargent, Thomas, (1976) "Interest Rates and Expected Inflation: A Selective Summary of Recent Research." Explorations in Economic Research, 3, pp. 303-325. and Neil Wallace, (1973) "The Stability of Models of Money and Growth with Perfect Foresight," Econometrica, 41, November, pp. 1043-48.

(1975) "Rational Expectations, the Optimal Monetary Instrument and the Optimal Money Supply Rule;" Journal of Political Economy, 83, Apri1, pp. 241-254.

(1976) "Rational Expectations and the Theory of Economic Policy," Journal of Monetary Economics, 2, April, pp. 1-44.

Shiller, Robert J. (1978) "Rational Expectations and the Dynamic Structure of Macroeconomic Models: A Critical Review." Journal of Monetary Economics, 4, January, pp. 1-44.

Stigl1tr, Joseph E. (1977) "Monopoly, Non-linear Pricing and Imperfect Information: The Insurance Market." Review of Economic Studies, 44, October, pp. 407-430.

(1979) "Equilibrium in Product Markets with Imperfect Information," American Economic Review, Papers and Proceedings, 69, March, pp. 339-345.

Taylor, John, (1977) "Conditions for Unique Solutions in Stochastic Macroeconomic Models with Rational Expectations" Econometrica, 45, September, pp. 1377-85. 
.Taylor, John B. (1978) "Aggregate Demand and Staggered Contracts"; unpublished, Columb1a University.

.Tobin, James (1956) "The Interest Elasticity of Transactions Demand for Cash." Review of Economics and Statistics, 38, August, pp.241-247.

and Willem Bufter, (1978) "Fiscal and Monetary Policles, Capital Formation and Economic Activity," in George von Furstenberg ed. The Government and Capital Formation, Ballinger.

.Wilson, Charles A. (1977) "A Model of Insurance Markets with Incomplete Information," Journal of Economic Theory, 16, December, pp. 167-207.

(1979) "Equilibrium and Adverse Selection," American Economic Review, Papers and Proceedings, March, pp. 313-317.

.Wong, Choung-ituey and Øystein Pettersen (1976) "Financial Programming in the Framework of Optimal Control: An Expository Note." International Monetary Fund, Research Department, Departmental Memorandum, December 10. 